\title{
Tight Junctions: A Barrier to the Initiation and Progression of Breast Cancer?
}

\author{
Kieran Brennan, Gozie Offiah, Elaine A. McSherry, and Ann M. Hopkins \\ Department of Surgery, Royal College of Surgeons in Ireland, Dublin, Ireland \\ Correspondence should be addressed to Ann M. Hopkins, annhopkins@rcsi.ie
}

Received 10 July 2009; Accepted 27 August 2009

Academic Editor: Karl Chai

Copyright ( $) 2010$ Kieran Brennan et al. This is an open access article distributed under the Creative Commons Attribution License, which permits unrestricted use, distribution, and reproduction in any medium, provided the original work is properly cited.

\begin{abstract}
Breast cancer is a complex and heterogeneous disease that arises from epithelial cells lining the breast ducts and lobules. Correct adhesion between adjacent epithelial cells is important in determining the normal structure and function of epithelial tissues, and there is accumulating evidence that dysregulated cell-cell adhesion is associated with many cancers. This review will focus on one cell-cell adhesion complex, the tight junction (TJ), and summarize recent evidence that TJs may participate in breast cancer development or progression. We will first outline the protein composition of TJs and discuss the functions of the TJ complex. Secondly we will examine how alterations in these functions might facilitate breast cancer initiation or progression; by focussing on the regulatory influence of TJs on cell polarity, cell fate and cell migration. Finally we will outline how pharmacological targeting of TJ proteins may be useful in limiting breast cancer progression. Overall we hope to illustrate that the relationship between TJ alterations and breast cancer is a complex one; but that this area offers promise in uncovering fundamental mechanisms linked to breast cancer progression.
\end{abstract}

\section{Introduction}

Breast cancer is the most common form of cancer among women in North America and the majority of European nations. Each year, it is diagnosed in an estimated 1 million women worldwide, and is the cause of death of over 400000 [1]. The incidence of breast cancer increases with age and doubles every 10 years until the menopause, supporting a link with hormonal status [2]. Specific life events associated with an enhanced breast cancer risk include reproductive factors, nulliparity, radiation exposure, hormonal status, obesity, family history, and many others [3,4].

Breast cancer is a heterogeneous disease in which genetic and environmental factors interact to initiate carcinogenesis. However, $10 \%$ of all breast cancer cases have a strong hereditary component in which half carry a deleterious mutation in the high penetrance genes BRCA1 or BRCA2. These account for over $50 \%$ of familial breast cancer cases and confer a lifetime risk of $60-80 \%$ [5]. In its simplest forms, breast cancer can be subclassified into preinvasive and invasive disease categories. Neoplastic conversion to invasive cancer likely occurs sometime during the preinvasive histological phases of usual hyperplasia, atypical hyperplasia, and ductal carcinoma in situ (DCIS) [6-11]. One hypothesis suggests the existence of genetically distinct subgroups of DCIS, only some of which subsequently progress to invasive ductal carcinoma (IDC) [12-14]. An alternate theory proposes that DCIS progresses from low to high grades and then to invasive cancer with progressive accumulation of genomic changes. However, the large extent to which the genome is altered in DCIS indicates that genomic instability most likely precedes phenotypic evidence of invasion, and highlights the importance of environmental components on the development of invasive cancer [6].

Recent data have shown significant reductions in the mortality rates of breast cancer, which have been mainly attributed to improved screening techniques, improved surgical and radiotherapy interventions and also the utilization of traditional chemotherapies in a more efficacious manner. Large-scale translational research studies have also identified many important new biomarkers predictive of poor prognosis in breast cancer patients [15-17]. However, much remains 
to be understood about the development and progression of breast cancer. Our review will address the contribution of altered epithelial cell-cell adhesion to the development and progression of breast cancer, with particular emphasis on the role of the tight junction (TJ) adhesion complex in these processes.

\section{TJs and Physiological Cell-Cell Adhesion}

Cell-cell adhesion is necessary for the assembly of coherent sheets of barrier-forming epithelial cells that line the breast ducts and lobules. However cell-cell contacts are far from being static structures which maintain barriers by simply holding cells together. In fact cell-cell contacts undergo constant remodelling to allow the extrusion of apoptotic cells as well as the incorporation of newly differentiated epithelial cells, derived from progenitor cells, without loss of barrier function [18]. Cell-cell contacts must also be remodelled depending on the developmental stage of the breast, whether in response to increased proliferative demands of puberty and pregnancy, increased differentiation during lactation, or increased apoptosis in conjunction with gland remodelling during involution [19]. Finally, during wound healing, epithelial cells can undergo coordinated movement and proliferation to bridge the wound, and establish new cell-cell contacts with epithelial cells from the opposing side of the wound [20].

Epithelial cell-cell contacts consist of three main adhesive structures: tight junctions (TJs), adherens junctions and desmosomes, as well as gap junctions for cell-cell communication (Figure 1). In polarized epithelial cells the tight junction and adherens junction are asymmetrically distributed at the apical region of the lateral membrane forming the apical junctional complex, which encircles the apex of the cells and marks the border between the apical and basolateral membrane domains [21]. These adhesive structures are composed of integral membrane proteins that link the neighbouring cells through homophilic and heterophilic interactions, and the presence of cytoplasmic scaffolding proteins that organise signalling complexes and anchor cell-cell contacts to the actin cytoskeleton (or intermediate filaments in the case of desmosomes) [22].

In this review we will first outline the protein components of the TJ and discuss the biological roles of the $\mathrm{TJ}$ complex, review how alterations in these roles could facilitate breast cancer initiation or progression, and finally mention pharmacological approaches towards targeting TJ proteins that could have value in limiting breast cancer progression.

2.1. Protein Components of the TJ. Proteins within TJ can be grouped into integral membrane proteins, scaffolding proteins, or signalling proteins as outlined in what follows.

2.1.1. Integral Membrane Proteins. The first protein to be discovered at the tight junction, occludin [23], is a $68 \mathrm{kDa}$ transmembrane protein with two extracellular loops and a long cytoplasmic tail containing several protein-binding domains. It exists in unphosphorylated and serine/threonine

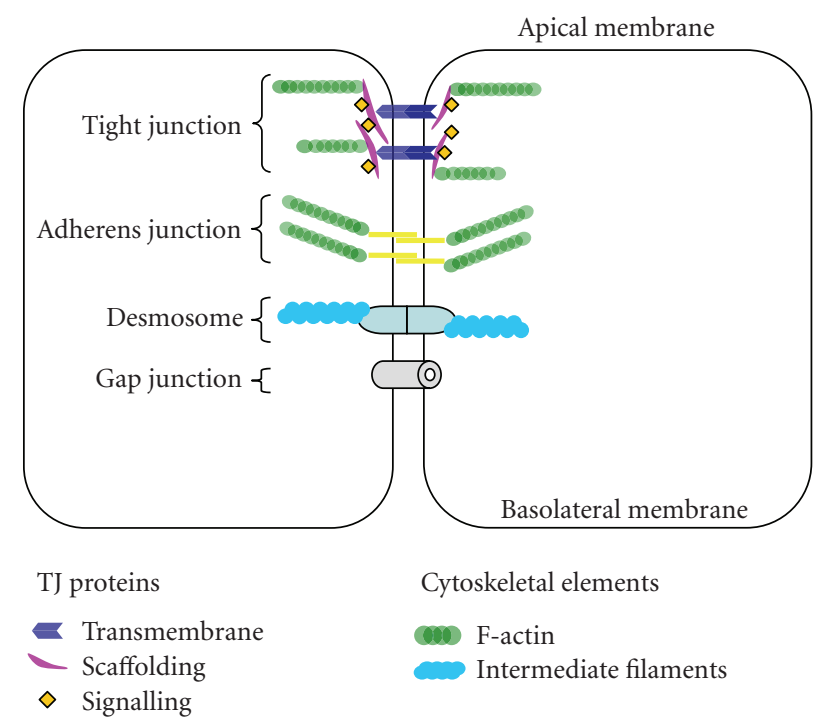

FIGURE 1: Epithelial cell-cell adhesion complexes.

and tyrosine phosphorylated forms, with the degree of phosphorylation affecting tight junction assembly, transepithelial resistance, and localisation of occludin to the tight junction $[24,25]$. Several enzymes are involved in regulating these phosphorylation events, including PKC [26], CK2 [27], and the nonreceptor tyrosine kinase c-Yes [24].

The claudin family of TJ transmembrane proteins consists of 24 members between 20 and $27 \mathrm{kDa}$ in size, mostly with short cytoplasmic tails which bind to the PDZ (PSD95, Dlg, and ZO-1) domains of other TJ proteins including ZO-1, -2, and -3 [28]. Various claudins are expressed in a tissue-specific manner, with the subtle differences in their extracellular loops determining ion selectivity of the paracellular pathway [29, 30].

The junctional adhesion molecule (JAM) family consists of "JAM-A, -B, -C, -L and JAM-4,..." which are found at TJs of epithelial/endothelial cells and on various hematopoietic cells [31-33]. They contain an extracellular region with two Ig-like domains, a single transmembrane domain, and a short intracellular tail with a PDZ binding motif through which JAM-A interacts with the PDZ proteins AF6, Par-3, CASK, MUPP1, and ZO-1 [34-38].

The coxackie and adenovirus receptor (CAR) is a $46 \mathrm{kDa}$ integral membrane protein with one transmembrane region, a long cytoplasmic tail, and an extracellular region composed of two Ig-like domains. The carboxyl terminal domain of CAR contains a PDZ binding motif which interacts with ZO1, MUPP-1, MAGI, and PICK1 [39-41]. CAR is required for MUPP1 localization at the tight junction [39].

Crumbs3 (CRB3) is a single-pass membrane protein located at the apical cell membrane with a small fraction in the upper part of tight junctions of epithelial cells. It is involved in the establishment of cell polarity in mammalian epithelial cells and regulates the morphogenesis of tight junctions. CRB3 interacts with PAR6, PALS1, and PATJ [42-45]. 
Tricellulin is a $66 \mathrm{kDa}$ membrane protein which has multiple phosphorylated states but exists predominantly in its unphosphorylated form. It is enriched only at tricellular tight junctions, where it enforces the barrier function of epithelial cell sheets [46].

2.1.2. Scaffolding and Signalling Proteins. Zona occludens (ZO) family members $\mathrm{ZO}-1, \mathrm{ZO}-2$, and $\mathrm{ZO}-3$ belong to the MAGUK family of TJ-associated scaffolding proteins. ZO proteins interact with each other $[47,48]$ as well as with cingulin [49], claudin-1-8 [28], actin [47], $\alpha$-catenin [50], and occludin [47]. Interactions vary between family members, as illustrated by the fact that ZO-3 can interact with PATJ [51] while only ZO-1 can interact with JAMs A-C $[34,37]$, EGFR [52], and AF-6 [53]. In addition, ZO-1 binds the Y-box transcription factor ZONAB and the heat shock protein Apg-2 [54, 55].

Afadin (AF-6) is a Ras-binding, PDZ domain-containing scaffolding protein which interacts with nectin, JAM-A, ZO1, profilin, ponsin, Rap1, and signal-induced proliferationassociated protein 1 (SPA-1, a Rap1 GTPase activating protein) $[35,56-58]$. The nectin-AF-6 complex is involved in the formation of adherens and tight junctions.

The membrane associated guanylate kinase inverted (MAGI) family consists of MAGI-1, MAGI-2, and MAGI3. MAGI-1 was first identified in mouse as a protein interacting with k-RasB [59]. MAGI-2 was initially identified in rat as a protein interacting with $\mathrm{N}$-methyl-D-aspartate receptors (NMDA-Rs) and neuronal cell adhesion proteins [60]. MAGI-3 was identified in a two-hybrid screening as a protein interacting with the tumour suppressor PTEN [61], and Receptor Tyrosine Phosphatase beta [62].

Cingulin is a $140-160 \mathrm{kDa}$ protein consisting of a globular "head" domain, a coiled-coil "rod" domain, and a globular "tail" domain. In vitro binding studies have revealed that cingulin interacts with various components of tight junctions including JAM, ZO-1, ZO-2, ZO-3, myosin and $\mathrm{F}$-actin, suggesting a role for cingulin as a linker between the TJ membrane and F-actin $[49,63-65]$. Cingulin also functions to sequester and inactivate the RhoA activator GEF-H1 at TJs, resulting in inhibited RhoA signalling and G1/S phase transition $[66,67]$. Loss or mutation of cingulin does not perturb the formation of tight junctions, but results in increased claudin-2 expression and cellular proliferation, which are dependent on increased RhoA activity [68].

Amot is a scaffolding protein with a coiled-coil region and a PDZ binding motif [69], which forms a complex with the Rho GTPase-activating protein Rich1 and is targeted to the tight junction interaction with PATJ or MUPP1 [70, 71]. Two Amot-like proteins, JEAP and MASCOT, have also been identified as TJ proteins $[72,73]$ which interact with MUPP1 [70].

Atypical protein kinase $\mathrm{C}$ is located at the $\mathrm{TJ}$ and plays a crucial role in maintaining tight junction structure and cell polarity through phosphorylation and stabilization of junction-associated proteins $[74,75]$. Activation of classical protein kinase $\mathrm{C}$ and novel protein kinase $\mathrm{C}$ has been shown to disassemble TJs [76].

\subsection{Biological Functions of the TJ Complex}

2.2.1. Gate and Fence Function. In polarized epithelial cells the $\mathrm{TJ}$ forms a belt-like structure at the apical-most region of the lateral membrane, and represents a boundary between apical and basolateral membranes [77]. The main functions attributed to TJs are the regulation of paracellular permeability (gate or barrier function), and the formation of a physical barrier preventing intramembranous movement of lipids and proteins (fence function). Gate function regulates the passage of ions and solutes across epithelial sheets in an organ-specific manner, and can be modified depending on the specific requirements of the organ [30, 78]. Fence function is required to maintain asymmetric distribution of membrane components and to develop membrane polarity [77]. Epithelial barrier function relies heavily on the claudin family of TJ proteins, which form strands controlling selective permeability by forming sizeand charge-selective aqueous pores [30, 78, 79]. Epithelial fence function on the other hand is not solely reliant on one subset of integral membrane proteins but instead requires cooperation between integral membrane proteins and several TJ scaffolding proteins and signalling molecules [80].

2.2.2. Regulation of Adhesion and Migration. Epithelial cells control adhesion to the basement membrane and extracellular matrix to maintain an intact barrier that can reseal quickly in response to injury. Breaching of the epithelial barrier stimulates cells to extend protrusions into the wound space, which can result in TJ disruption and release of proteins such as PATJ, Par3, aPKC [81], Cdc42, and Par6 [82] from their scaffolds. Retargeting these (and other) proteins to the migrating edge helps polarize migrating cells in the direction of movement via reorientation of the Golgi, centrosome and the microtubule cytoskeleton along the axis of migration $[82,83]$.

2.2.3. Regulation of Polarity and Differentiation. TJs regulate epithelial polarity by controlling the assembly of three main polarity complexes; the CRB3 complex, the Par complex, and the Scrib complex, which will be discussed in the following section. The apical junctional complex serves to restrict the movement of these complexes in order to form distinct apical and basolateral domains. Apico-basolateral polarity allows for terminal differentiation of epithelial barriers by apical orientation of the trans-Golgi network, which can sort membrane proteins toward either apical or basolateral membranes. Specialized membrane trafficking leads to the accumulation of receptors and channels in either apical or basolateral membranes, allowing electrochemical gradients to develop across epithelial sheets $[84,85]$.

From the afore-mentioned information, it can be observed that TJ proteins exert fundamental influences over cellular processes that regulate polarity, differentiation and migration; all of which are processes central to cancer progression. Therefore, TJ and other cell-cell adhesion proteins are gaining increasing attention in breast cancer research [86-89]. Most work to date has focused on adherens junction 
proteins (such as cadherins) in breast cancer progression; and in fact loss of E-cadherin is a defining feature of lobular breast carcinoma $[90,91]$. However, TJ proteins have also been found to be dysregulated in several human cancers including breast, and have been suggested as promising targets for cancer detection, diagnosis, and therapy [88]. In this review, we will attempt to summarize current knowledge on the impact of TJ proteins on breast cancer progression; based on the ability of TJs to control polarity, differentiation, and migration.

\section{The Contribution of TJ Alterations to Breast Cancer}

Our review will focus on three aspects whereby functional alterations in TJs may impact breast cancer progression by altering cell polarity, cell fate, and cell migration. For a broad overview of TJ alterations in cancer metastasis of other tumours, the reader is directed to a recent review [92].

\subsection{TJ-Mediated Alterations in Polarity-Role in Breast Can-} cer Progression. Formation of the TJ adhesion belt allows the targeting of scaffolding proteins which regulate the cellular polarity machinery. This machinery is composed of three polarity complexes which identify separate regions of the cell. These polarity complexes were originally identified in C. elegans and Drosophila, but have been found to be highly conserved in mice and higher mammals. The CRB complex identifies the apical region due to apical concentration of CRB3 [93], which is targeted to the tight junction by PATJ and ZO-3 [51, 94]. The Par complex localizes at TJs through interactions between Par-3 and JAM-A [38]. Finally, the Scribble (Scrib) complex identifies the basolateral region of the cell, and is targeted to adherens junctions through interaction of Scrib and Dlg with E-cadherin [95-98].

The CRB complex is the most apically located polarity complex in epithelial cells, and acts as an apical anchor for the targeting of cytoplasmic proteins during polarisation [93]. It is composed of the transmembrane protein CRB3 and the scaffolding proteins PALS1 and PATJ. Several components of the CRB complex are reportedly dysregulated in breast cancer. For example, CRB3 and PATJ expressions were shown to be repressed by the transcription factor ZEB1, which is upregulated in invasive ductal and lobular breast cancers [99]. ZEB1 has been implicated in epithelial to mesenchymal transition (EMT), a dedifferentiation programme associated with cancer metastasis in which epithelial junctions and cell polarity are disrupted, contributing to increased cell motility [100]. PATJ also binds a negative regulator of mTOR called TSC2, which regulates survival, apoptosis, and cell cycle progression [101-103]. The mTOR pathway has been shown to be frequently deregulated in various cancers including breast $[16,18]$. Massey-Harroche et al. reported that PATJ knockdown in intestinal epithelial cells resulted in the upregulation of the mTOR pathway [104]; and it is possible that loss of PATJ in cancers such as breast could facilitate tumour progression by allowing the prosurvival effects of mTOR activation to go unchecked.
PATJ is also important for the proper localisation of claudin1, ZO-3, CRB3, occludin, aPKC, and ZO-1 at TJs [51, 94, 105]. Loss of PATJ could, therefore, also promote "leaky" junctions, resulting in increased access of luminal growth factors to the basolateral epithelial surface. It is intriguing to speculate that this leakiness could promote tumour progression by feeding the developing tumour, as proposed in the nutritional model of carcinogenesis [106]. This along with the dysregulation of aPKC has the potential to induce substantial increases in proliferation as well as a loss of polarity, all of which are hallmarks of cancer progression.

Other members of the CRB polarity complex could also play a role in breast cancer progression. Knockdown of the PALS1 binding partner lin-7 in renal epithelial cells was shown to reduce expression levels of PALS1, PALS2, Dlg2, Dlg3, and PATJ [107]. A resulting failure to recruit aPKC to TJs resulted in reduced epithelial barrier function, delayed polarization, and impaired lumen clearance in threedimensional morphogenesis models [107, 108]. Loss of PALS1 also resulted in defects in E-cadherin trafficking [109], which, taken together, suggests that analagous disruption of the CRB3 complex during breast cancer could impair barrier function and polarity, and potentially facilitate occlusion of breast duct lumens with tumour cells.

The PAR complex is made up of Par3, Par6, aPKC, and Cdc42/Rac1. Recently, Par6B was reported to be transcriptionally upregulated in breast cancer tissues by quantitative PCR [110]. Interestingly, MCF-10A breast epithelial cells overexpressing Par6 polarized normally in three-dimensional culture models, but showed higher proliferation rates which were dependent upon Par6 interactions with aPKC and Cdc42 [110]. Increased Par6 signalling has also been reported in MCF-10A cells overexpressing activated ErbB2 [111, $112]$, the growth factor receptor which is amplified in 25$30 \%$ of breast cancers and which identifies a subtype of highly aggressive tumour [113]. Activation of ErbB2 in these cells induces the formation of multiacinar structures with abnormal filled lumens, in a manner dependent on interactions of ErbB2 with the Par6-aPKC complex [112]. Mutation of Par6 in cells overexpressing activated ErbB2 was observed to restore lumen formation, suggesting an inhibitory tone of Par6-ErbB2 interactions on apoptotic clearance of developing lumens [112]. The role of Par6 in apoptosis is suggested to be due to the activation of aPKC by Par6 [114]. Par6-aPKC interactions have also been shown to activate Rac1 in non-small cell lung cancer cells, resulting in anchorage-independent growth and invasion through activation of matrix metalloproteinase-10 (MMP10) expression $[115,116]$. Thus dysregulation of Par6 in cancer cells has the potential to impact tumour progression via direct effects on polarity, migration, and even apoptosis.

In contrast to Par6, Par3 expression has been found to be reduced in oesophageal squamous cell carcinomas in association with lymph node metastasis and poor differentiation [117]. Certain forms of EMT have also been shown to downregulate Par3 expression, with Par3 overexpression capable of rescuing the loss of E-cadherin during EMT in a rat kidney epithelial model [100]. Given the putative link between EMT induction and breast cancer progression, it 
will be interesting to uncover whether Par3 expression might also be lost in breast cancer. Since Par3 regulates Par6, loss of Par3, in turn, is likely to exert an influence over the control of proliferation, polarity, and apoptosis resistance by Par6 signalling in cancer cells.

The scribble complex is an evolutionarily conserved complex consisting of three members, Scrib, lethal giant larvae homolog (LGL), and discs large homolog (DLG). Loss of function mutations of scrib, DLG, and LGL in Drosophila have demonstrated abnormal cell polarity with increased proliferation without tumour cell overgrowth, possibly due to increased apoptosis [118-120]. Scrib has been shown to colocalise with DLG and E-cadherin at adherens junctions [98], and is required for formation of this junction and proper localisation of DLG and LGL as well as apical targeting of CRB3 [97, 121]. Scrib staining was shown by immunohistochemistry to be reduced and mislocalized in human breast cancer tissues [98, 122]. Zhan et al. have suggested a role for Scrib in breast cancer development by reducing apoptosis in c-myc over-expressing breast epithelial cells [122]. Activation of c-myc enhanced the formation of a Scrib complex which activated the small GTPases Rac and $\mathrm{Cdc} 42$ and increased the expression of a proapoptotic protein Bim. Conversely, loss of Scrib suppressed the ability of c-myc to induce Bim expression [122]; suggesting a mechanism for reduced apoptosis and increased resistance of breast cancer cells to cytotoxic stresses in the event of Scrib loss.

LGL is a cytoplasmic protein which is targeted to the lateral epithelial membrane during polarisation [123]. Like CRB3 and PATJ, LGL1 is repressed by the transcription factor ZEB1, whose expression is upregulated in several forms of breast cancer [99]. Therefore, dysregulation of LGL may play a role in EMT events associated with breast cancer progression. Alterations in the final member of the Scrib complex, DLG, may also play a role in cancer progression. DLG3 has been shown to be reduced in gastric carcinoma [124]; whilst overexpression of DLG1 and DLG3 inhibits cellular proliferation via a block in G1/S phase transition of the cell cycle $[125,126]$. DLG4 interacts with Frizzled proteins to regulate the WNT signalling pathway [127], inappropriate activation of which has been implicated in oncogenesis due to myriad influences on cell adhesion, migration, proliferation, and cell death [128]. DLG1 and DLG3 also regulate WNT signalling through DLG3-mediated $\beta$-catenin degradation and the binding of DLG1 to APC and by modulating the antiproliferative effects of APC [125, 126, 129]. In unpolarized cells, DLG1 is ubiquitinated and degraded, and only upon junctional formation is it hyperphosphorylated and stabilised [130]. This indicates that the integrity of cell-cell contacts regulates the Scrib polarity complex and that disruption of this complex promotes dysregulated growth and resistance to apoptosis.

As illustrated above, alterations in CRB3, Scrib, and Par polarity complexes can promote proliferation, cell cycle progression and evasion of apoptosis as a result of disrupted apical-basolateral polarity in a variety of models. Although several of the seminal observations were originally made in Drosophila and C. elegans, many findings have since been confirmed in higher mammals and during in vitro studies on human breast and other carcinoma cell lines. Thus insights from simple organismal models of polarity are highly relevant not only to the control of normal human physiology by the polarity machinery but also to the development of many cancers including breast. However, abnormalities in the polarity machinery are only one of several ways in which TJ dysfunction can impact upon breast cancer progression. The role of TJ-mediated alterations in cell fate will be discussed in the following section.

3.2. TJ-Mediated Alterations in Cell Fate-Role in Breast Cancer Progression. Although cancer is frequently considered as a disease of abnormal proliferation, cancer progression is not determined solely by proliferative advantage within tumour cells. Other factors such as apoptosis resistance and the ability to bypass senescence pathways contribute to an environment supporting breast cancer progression. The role of individual TJ proteins in modulating these aspects of breast cancer progression will be addressed in what follows.

Occludin expression is known to be downregulated in several cancers including breast [131]; its loss correlating with glandular dedifferentiation and progression of human endometrial, colorectal, and lung carcinomas [132-134]. In recent studies, occludin overexpression was found to promote detachment-induced apoptosis (anoikis) in AC2M2 murine breast carcinoma cells, while endogenous occludin re-expression correlated with downregulation of apoptosisinhibitory genes (bcl-2, survivin) and upregulation of apoptosis-inducing genes (apaf-1, bax) [135]. TUNEL assays also revealed that HeLa cells constitutively overexpressing wild-type occludin exhibited increased sensitivity to oxidantinduced apoptosis. Occludin overexpression was also shown to induce premature senescence in AC2M2 cells, as assessed by increased senescence-associated $\beta$-galactosidase enzymatic activity and the upregulation of negative cell cycle regulators such as p16INK4A, p21Waf1/Cip1, and p27Kip1 but not p53 [131]. The ability of cells to autoinduce growth arrest based upon the expression of TJ proteins such as occludin could has a profound inhibitory effect on tumour growth, and illustrates how significant a loss of such proteins could be for tumour progression.

Similarly to occludin, claudin-1, $-4,-6$ have also been reported as downregulated in breast cancer [131, 136-139]. Suppression of endogenous claudin-6 expression by siRNA in MCF7 breast cancer cells increases resistance to oxidantinduced apoptosis and anoikis, thereby promoting colony formation in two- and three-dimensional cultures [140]. In a complementary approach, forced induction of claudin-1 expression in MDA-MB-361 breast cancer cells resulted in elevated apoptosis in three-dimensional cultures. Enhanced apoptosis correlated with increased spheroid size, suggesting a positive effect of nutrient and growth factor diffusion into spheroids [136]. This supports the hypothesis that cancer formation may be promoted in premalignant epithelial tissues that have become chronically leaky to growth factors [141]. Claudin-1 may also play a role in the control of cell fate, with observations of increased expression in senescent 
breast epithelial cells [139] and reduced expression in invasive breast cancers.

In an interesting contrast, expression of claudin-3, -4 and -7 have actually been observed to increase in both breast and ovarian cancers [88, 142-145]. Overexpression of claudin-3 and -4 in HOSE-B ovarian cells enhanced cell survival in clonogenic assays [88], further supporting a role for either upregulation or downregulation of key claudins in the controlling cancer cell fate.

Occludin-interacting proteins $\mathrm{ZO}-1$ and $\mathrm{ZO}-2$ have also been shown to be repressed with cancer progression $[52,146,147]$, where decreased ZO-1 staining correlates with decreased glandular differentiation of breast tumour specimens [146]. ZO-1 and ZO-2 regulate cell cycle progression and proliferation in a cell density-dependent manner [148-151] through transcription factors such as ZONAB. ZONAB localizes to the nucleus and the TJs in proliferating MDCK cells [151], but is not detectable in the nucleus of nonproliferating high-density cells [148]. Evidence indicates that cytoplasmic ZONAB immunoprecipitates with both CDK4 and cyclin D1 and assists in the nuclear accumulation of cdk4, promoting G1/S phase transition and cell cycle progression [148]. ZONAB also upregulates ErbB2 expression [151], which (as discussed earlier) could profoundly impact progression of a subset of breast cancers. ZO-2 blocks cell cycle progression by downregulating cyclin D transcription and inhibiting cdk2 and cdk4 [150, 152]. ZO-2 also controls cyclin D expression and interacts with the transcription factors jun, fos, and C/EBP to regulate proliferation [150]. Thus, it can be observed that $\mathrm{ZO}$ proteins control cellular proliferation in a density-dependent manner by sequestering transcription factors at the tight junction. Loss of $\mathrm{ZO}$ proteins during breast cancer may, therefore, promote proliferation via a loss of control over cell cycle progression.

Finally, in addition to the many TJ structural proteins which exert regulatory control over cell fate, signalling proteins affiliated with the TJ complex could also play a part in breast cancer progression. For example, many small GTPases have been described to affiliate with the TJ complex [153]. As key signalling molecules which regulate actin dynamics, GTPases profoundly impact processes that are central to cancer initiation and progression [154]. For example, RhoA promotes cell cycle progression through the regulation of p21 and p27 levels [155]. TJs regulate RhoA activity by cingulin-mediated sequestration of the RhoA activator GEF-H1 and inhibition of G1/S phase transition [67]. Increased GEF-H1 levels can arise by mutations in p53 [156], a frequent genetic alteration observed in breast cancer.

These alterations suggest a relationship between $\mathrm{TJ}$ alterations and the malignant potential of several carcinomas, via deficits in controlled proliferation, regulated cell cycle progression and apoptosis. This suggests that the dysregulation of cell-cell contact machinery may be a prerequisite for cancer progression in order to turn off specific epithelial regulatory pathways. The loss of membrane polarity via tight junction abnormalities may also alter cell-cell and cell-extracellular matrix interactions, and might, therefore, facilitate migration, invasion, and the development of metastasis, which will be reviewed in the following section.

\begin{abstract}
3.3. TJ-Mediated Alterations in Cell Migration-Role in Breast Cancer Progression. As discussed earlier, altered cellcell adhesion contributes to a loss in polarity and contact inhibition, culminating in uncontrolled proliferation during breast cancer initiation. There is also evidence that altered cell adhesion plays a fundamental role in breast cancer progression by freeing tumour cells from both neighbouring cells and the underlying matrix; and in parallel by conferring a motile or migratory advantage to cells during invasion and metastasis $[19,157,158]$. In this section, we will attempt to summarize current knowledge on the impact of TJ proteins on breast cancer progression.
\end{abstract}

3.3.1. TJ Integral Membrane Proteins. Occludin has been linked with cancer progression in endometrial carcinoma; where decreasing expression was correlated with increasing grade, myometrial invasion, and lymph node metastasis [132]. Forced expression of occludin in breast cancer cells has been shown to decrease cancer cell migration and invasion both in vitro and in vivo [135]. Interestingly, the occludin gene can be silenced by hypermethylation, and it may be that the methylator phenotype promotes tumourigenic, invasive, and metastatic properties of cancer cells [135].

A wealth of evidence has also implicated the claudin family in breast cancer cell migration. Tumours with low expression of claudin-3, -4 and -7 and high expression of stem cell and epithelial-mesenchymal markers were recently shown to associate with poorer overall survival [159], as mirrored in other studies [160]. Like occludin, claudin-1 protein levels are reportedly reduced in breast tumours and breast cancer cell lines [161]. Importantly, claudin-1 has been detected in the membranes of normal breast ductal epithelial cells and in some DCIS tumour cells, but is frequently absent from invasive tumours [142]. Furthermore, claudin-1 expression has been demonstrated as a good predictor of disease recurrence and malignant potential in breast cancer. Morohashi et al. demonstrated that recurrent breast tumours displayed significant reductions in claudin-1 expression compared to primary tumours; while reduced claudin-1 expression has also been associated with lymph node involvement and decreased disease-free survival [162]. Taken together, these data suggest a role for claudin-1 in invasion and metastasis. Furthermore, MDA-MB-361 breast cancer cells deficient in claudin-1 grow as multicellular filled spheroids in three-dimensional cultures and re-expression of claudin-1 induces central lumen formation [136]; perhaps by nutritional deprivation of innermost cells inducing apoptosis as already discussed [141].

Other than claudin-1, the loss of several other family members has been reported in breast cancer [142, 162166]. Osanai et al. demonstrated that decreased expression of claudin- 6 in breast cancer cells (by siRNA or epigenetic silencing) increases MMP activity, likely facilitating increased cancer cell migration and invasion [140]. Subsequent reintroduction of claudin- 6 increased cellular adhesion and 
abrogated enhanced invasion and migration. Expression of claudin-7 has been shown to be reduced in IDC cells compared to those of the normal breast [164], and reduced in fine needle aspirates from IDC patients [166]. In both studies, loss of claudin-7 expression also correlated with increasing tumour grade and metastatic disease. In an intriguing study, treatment of MCF7 breast cancer cells expressing high levels of claudin-7 with HGF/scatter factor (which decreases cell-cell adhesion) led to a dramatic decrease in claudin7 expression, further linking the loss of claudin-7 and cell cohesion in breast cancer [164]. Most recently, forced expression of claudin-16 in MDA-MB-231 breast cancer cells has been reported to induce junctional formation and concurrently reduce aggressive and motile behaviour in vitro and in vivo [165].

In contrast to the reduced expression of several claudins, claudin- 3 and -4 have in fact been found to be elevated in breast cancer at both mRNA and protein level [143$145,167]$. Interestingly, overexpression of either claudin3 or claudin-4 in human ovarian epithelial cells has been reported to increase migratory and invasive capabilities [88]. As discussed later in this review, the ability of both claudins3 and -4 to function as receptors for Clostridium perfringens enterotoxin (CPE) [168] may provide a unique targeting mechanism to eliminate cancer cells overexpressing these proteins.

JAM proteins regulate numerous cellular adhesive processes including intercellular junction assembly [169], cell morphology [170], and leukocyte migration [171, 172]; while JAM-A dysregulation has recently been implicated in breast cancer $[173,174]$. JAM-A has been shown to regulate epithelial cell morphology and enhance $\beta 1$-integrin expression through modulation of Rap1 GTPase activity [170]. Since loss of tissue architecture and cell polarity is a prerequisite for breast cancer invasion and metastasis [175], disruption of JAM proteins may, therefore, play key roles in disease progression. Indeed, disruption of JAMA in a colonic carcinoma cell line was shown to convert cells from a stationery, polarized state to a migratory phenotype [176]. Recently, Naik et al. reported that JAM-A overexpression decreased migration and invasion in breast cancer cell lines, while knockdown of JAM-A expression enhanced invasiveness [174]. It was hypothesized, therefore, that the loss of JAM-A may correlate with poor clinical prognosis. However, a subsequent study by McSherry et al. revealed a significant association between high JAM-A gene and protein expression and poor survival in 2 large cohorts of human invasive breast cancer tissue specimens [173]. Furthermore, knockdown or antagonism of JAMA significantly decreased migration in MCF7 breast cancer cells expressing high endogenous levels of JAM-A. The apparent conflict between these two studies may be resolved by the fact that underexpression of JAM-A is likely to impair cellular adhesion and polarity (favouring tumour initiation), whereas overexpression of JAM-A could promote integrin-mediated migratory events that favour tumour progression. These data clearly implicate an imbalance of JAM-A expression patterns in breast cancer, and, as discussed later, may also form an interesting therapeutic target.
3.3.2. TJ Adaptor and Signalling Proteins. Few studies have specifically focussed upon the involvement of TJ adaptor and signalling proteins in breast cancer progression. However, ZO-1 loss has been linked to poor prognosis in breast cancer, with significantly reduced levels of TJ-associated ZO1 in patients with metastatic disease compared to those remaining disease-free [177]. Polette et al. also showed that expression of the matrix metalloproteinase MT1-MMP in invasive breast tumour cell lines is correlated with cytoplasmic localization of ZO-1 and with occludin loss [178]. ZO-1 has also been shown to be reduced or lost in ductal breast cancer tissues, in parallel with increased dedifferentiation [146]. Reduced ZO-1 expression has been significantly associated with reduced E-cadherin expression; whose loss is inextricably linked with lobular breast cancer [86]. Furthermore, ZO-1 has been reported to play an important role in controlling expression of the ErbB2 gene [179]. Downregulation of another family member, ZO-2, has also been reported in breast carcinoma [180]. In addition, $\mathrm{ZO}-2$ has been reported as crucial for the tumour-inducing capabilities of the Adenovirus type $9 \mathrm{E} 4$ protein. Expression of mutant ZO-2 protein lacking the $\mathrm{E} 4$ binding site inhibits E4-mediated tumour initiation in mammary glands [180, 181]. Taken together, it can, therefore, be considered that $\mathrm{ZO}$ proteins play important roles in the migratory events associated with breast cancer progression.

The Par complex (Par3-Par6-aPKC) promotes normal junction assembly by regulation of actin dynamics and is known to be altered in many cancers including breast (reviewed in [111]). Indeed, as previously addressed in this review, Par6, through association with aPKC and ErbB2, has been shown to disrupt apical-basal polarity and protect cells from apoptosis [112]. Other potential links between Par proteins and breast cancer involve EMT and the regulation of Rho family small G proteins including Rac [182], Rho [183], and Cdc42 [184]. For example, Par6 reportedly interacts with $\mathrm{TNF} \alpha$ in inducing EMT and TJ loss via degradation of RhoA [185]. In vitro experiments have revealed that the Par complex along with Rac signalling stabilizes frontrear polarization of noncontacting keratinocytes, thereby stimulating chemotactic migration [182]. Indeed, important biological processes such as migration and invasion are highly regulated by the Rho family. The Rho guanine nucleotide exchange factor (GEF) Tiam has been shown to increase with increasing breast tumour grade or cell line invasiveness [183]; and Tiam-mediated Racl activation has been correlated with tumour cell migration and invasion in vitro [186]. Integrin-mediated adhesion through Rho family GTPase activity has been reported as essential in regulating cell polarity and membrane protrusiveness [41]. Specifically, Rac1 and Cdc42 have been linked with integrinmediated motility and invasion through PI3K signalling in breast cancer cell lines [187]. Furthermore, the Rap GTPase Rap1 has been identified as a crucial signalling element downstream of $\beta 1$ integrin [170], responsible for regulating breast acinar structure and inducing mammary gland lumen formation [188]. Yet another signalling protein downstream of TJs, PKC [189], has also been linked to cancer initiation and progression. PKC overexpression and altered localization 
has been demonstrated in breast cancer [190], and PKC signalling is required for EGF-induced chemotaxis of human breast cancer cells [191].

This wealth of evidence indicates the potential involvement of several $\mathrm{TJ}$ adhesion cascades in the migratory events associated with breast cancer progression. Further studies on these proteins will allow a more comprehensive understanding of their behaviour and contributions to tumour progression, ultimately defining candidate breast cancer prognostic markers. The study of compounds designed to specifically target and block the action of adhesion proteins involved in cancer invasion could be of substantial therapeutic benefit in preventing breast cancer invasion.

\section{TJs and Breast Cancer Drug Therapies}

Targeted therapeutic agents for breast cancer represent a growing proportion of new drugs entering clinical testing. Since carcinogenesis is a multistep process characterized by alterations in many key growth and development pathways, there are numerous opportunities for pharmacologic targeting. Selection of appropriate drug targets and the ability to effectively deliver drugs to those targets are pivotal issues in drug development. This section will review current knowledge on TJs as breast cancer drug targets, and as targets for therapeutic modulation of cancer drug delivery.

In spite of the regulatory influences exerted by TJs on diverse processes relevant to cancer progression (as discussed in previous sections), there are currently no cancer therapies on the market which specifically target TJs. However, clues to potential TJ targets of value have come from many sources, including translational research studies involving patient databases. For example, overexpression of claudin- 3 and -4 proteins has been demonstrated in over $90 \%$ of primary breast carcinomas in a patient group of 188 [192], and in $60-80 \%$ of breast tumours in a tissue microarray of 314 patients [193]. Claudin-3 and -4 overexpression has also been noted in other neoplasias including ovarian, prostate, pancreatic, and endometrial [193-196]. These proteins form an intriguing potential target for cancer therapies, since both claudin-3 and -4 have been identified as the receptor for Clostridium perfringens enterotoxin (CPE) and the only claudin family members capable of mediating CPE binding and cytolysis [195-198].

CPE is a well-known virulence factor responsible for the gastrointestinal symptoms associated with C. perfringens type A food poisoning. By inducing permeability alterations in host intestinal epithelial cells, CPE induces cell death and epithelial desquamation. CPE is thus a multifunctional toxin with cytotoxic, TJ-damaging, and proinflammatory activities $[199,200]$. This ability of CPE to rapidly and specifically lyse cells expressing claudin-3 or -4 could potentially be exploited in the treatment of breast cancers overexpressing these proteins. Accordingly, it has been shown that claudin3 and -4 expressing breast cancer cell lines grown in cell culture and as xenograft tumours underwent rapid and dosedependent cytolysis in response to CPE treatment [143]. Even more promisingly, administration of CPE has been shown to reduce the growth of claudin-4 overexpressing human ovarian and pancreatic tumours [201]. Thus, local delivery of native CPE may be useful in the treatment of preneoplastic lesions such as DCIS and in neoadjuvant settings such as the locoregional control of locally advanced breast carcinoma, as well as in tumour downstaging to allow breast conservation therapy [143]. In addition to this, the documented ability of CPE to downregulate the epithelial barrier through interference with claudin- 3 and -4 may enhance local drug delivery for other treatment modalities. However, at least two caveats must be noted. Firstly (as discussed in prior sections), loss of TJ-based adhesion may imbalance cellular polarity which by itself is likely to be protumourogenic. Secondly, claudin- 3 and -4 are expressed in several normal human tissues including gut, lung, and kidney; therefore the potential high toxicity of $\mathrm{CPE}$ at doses used for systemic cancer therapy in animal models might limit its use in humans to local treatments [194, 202].

Claudin-3 and -4 overexpression in breast cancer could alternatively be targeted by toxin- or radionuclideconjugated antibodies, which would either destroy the cancer cells directly or target them for attack by the host immune system. The high sequence identity between claudin- 3 and -4 may allow generation of antibodies recognizing both proteins. Potential indications for anticlaudin antibodybased therapeutics include carcinomas of colorectal, breast, ovarian, and prostate origin [203].

In common with the discovery of claudin- 3 and -4 as the $\mathrm{CPE}$ receptor, other TJ proteins are known to be hijacked as pathogen receptors. The TJ protein CAR acts as the primary site for adenovirus attachment during infection, a feature which has been exploited as a delivery mechanism for gene therapies [204, 205]. CAR expression has been shown to significantly increase in breast tumour tissue along with increasing tumour grade [206]. Breast tissue samples showing elevated CAR expression have been associated with poor patient prognosis [206]. While the biological roles of CAR are incompletely defined, emerging evidence suggests that it may function in regulating cell proliferation [207]. Whether CAR overexpression in breast cancer could be successfully targeted by nonpathogenic components of the virus in order to diminish cancer cell proliferation remains an intriguing question.

Another TJ protein of interest for breast cancer drug discovery is occludin. Gumbiner et al. showed that occludin homotypic interactions and turnover, but not synthesis, could be affected by treating cells with peptides to the extracellular loop of occludin [208, 209]. Nusrat et al. also identified occludin peptides capable of binding TJ structural and signalling proteins [210], and demonstrated that the second extracellular loop of occludin regulates cellular transformation by oncogenes such as Raf-1 [211]. Given that occludin has been reported to be dysregulated in some breast cancers, it is intriguing to speculate that occludin could be a target for peptide-based cancer drugs.

Another TJ protein implicated in breast cancer progression is ZO-1, which as noted, has sequence homology with the Drosophila tumour suppressor Dlg, implying that ZO- 1 could possess similar functions as a tumour suppressor 


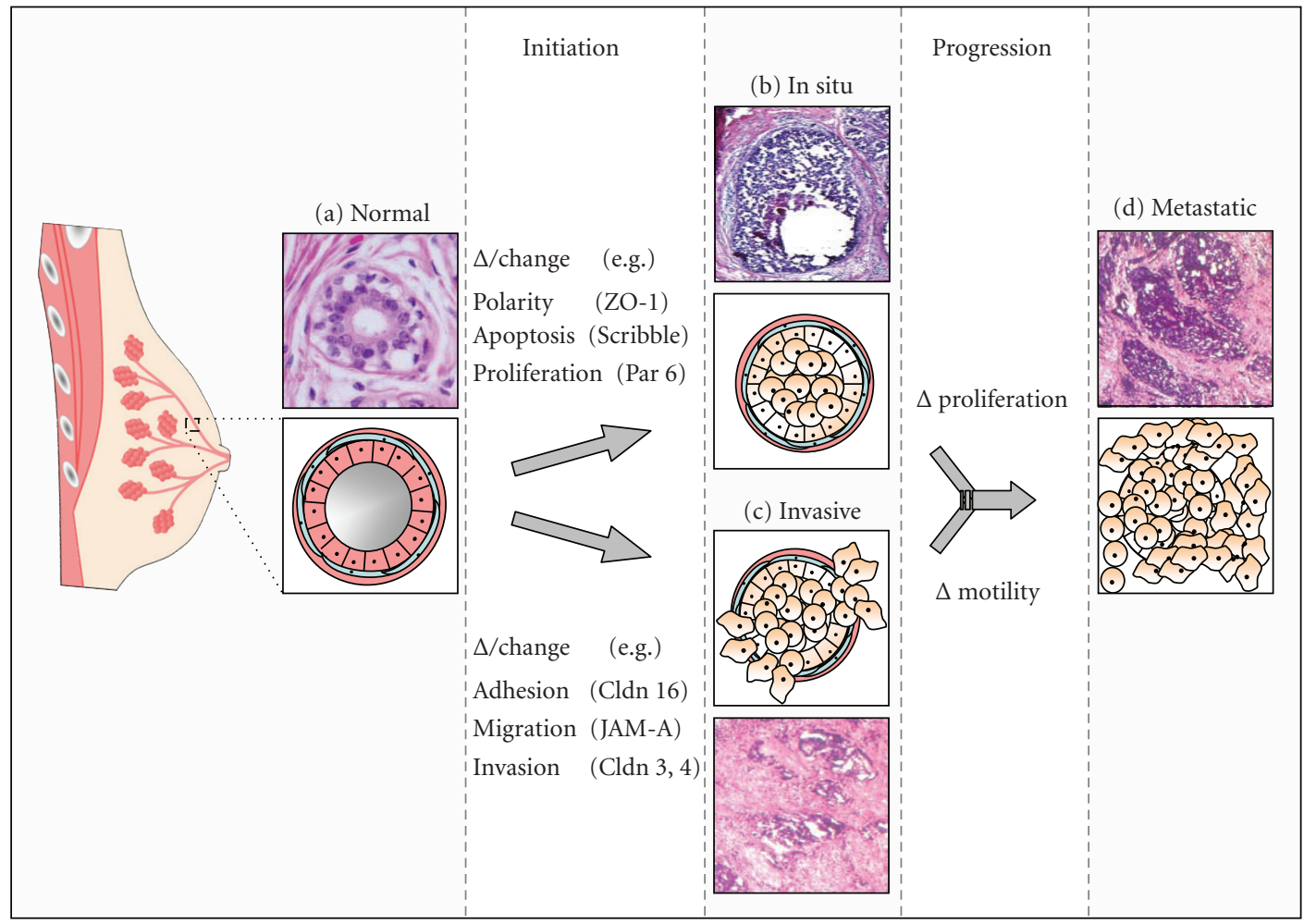

FIGURE 2: The potential influence of TJ proteins on breast cancer development. Breast cancer predominantly begins in luminal epithelial cells lining the normal breast ducts (a). Alterations in TJ proteins may lead to the initiation of breast tumourigenesis in at least two ways. Firstly, TJ alterations may favour decreased cellular apoptosis and increased proliferation leading to uncontrolled growth, such as is seen in ductal carcinoma in situ lesions (b). Secondly, TJ alterations may decrease cell adhesion and increase motility, facilitating cancer cell migration as seen during invasion and basement membrane breakdown in early primary invasive breast carcinoma (c). Breast carcinoma likely requires coordinated efforts of both increased proliferation and increased motility to progress to metastatic stages (d).

gene in mammalian epithelia [19]. Martin et al. observed decreased ZO-1 staining in several invasive breast cancer cell lines supporting the tumour-suppressive characteristics of ZO-1 [177].

Even more recently, it has been observed that increased JAM-A expression in human breast cancer tissues correlates with poor patient prognosis [173]. Since this mechanism is thought to involve promotion of integrin-mediated migratory events at the cell-matrix interface, it is, therefore, interesting to speculate that targeting JAM-A dimerization to reduce signalling could be a promising and novel target to reduce breast cancer cell motility during the early stages of invasion or metastasis.

A final point regarding TJs as breast cancer therapeutic targets relates to drug delivery. In order for therapeutic agents to reach their target in vivo, they must cross epithelial and/or endothelial barriers. Since the TJ is the primary regulator of paracellular transport across such cells [212], successful drug delivery may require modulation of TJ proteins to allow drug molecules to pass [213]. However, as before, it must be noted that disruption of TJ proteins purely for drug delivery purposes may itself promote cancer progression by upsetting homeostatic mechanisms of polarity, differentiation, cell fate, and migration which are tightly regulated by TJs in normal tissues.
To conclude this section, we note that therapeutic modulation of breast cancer via selective targeting of tight junction structural proteins is in its infancy. At present, CPE offers the best-developed strategy via targeting of claudin-3 and -4. While many signalling proteins and enzymes loosely affiliated with the TJ plaque may prove easier pharmacological targets, full discussion of this topic is beyond the scope of this review. Interested readers are directed to a comprehensive review by Schneeberger and Lynch [214]. It is clear however that further investigations into the cell biology of tight junctions are necessary to provide insights into putative future applications of TJ components as candidates for drug discovery to prevent or limit breast cancer progression.

\section{Conclusions}

Finally, we summarize the role of TJs in breast cancer initiation and progression as follows (see Figure 2). During the initiation phase of cancer, fundamental alterations in the TJ complex may impair its functional control over important cellular processes such as polarity and cell fate determination, or cell motility characteristics. Dysregulation of either of these aspects likely contributes to the pathologies which we recognise as ductal breast carcinoma in situ or invasive ductal 
carcinoma. Further dysregulation of a combination of these (and other) events is likely to be required for the most serious step of breast cancer progression, the transition to a metastatic phenotype.

It must be noted that there is not a simple relationship between TJ protein loss or gain and breast cancer. As we have described in this review, both loss and gain of $\mathrm{TJ}$ proteins can impart a growth advantage to breast cancer cells, as well as increased resistance to apoptosis, loss of polarity, and increased migratory or invasive characteristics. Through these important regulatory influences on polarity, cell fate and cell movement, we suggest that an intact and functional TJ complex acts as a barrier to the initiation and progression of breast cancer. However, any imbalance in the protein components of this complex (whether increased or decreased) will, in turn, imbalance the strict homeostatic control required to maintain breast tissue in its differentiated state, increasing the risk of inducing a pathologically dedifferentiated state such as breast cancer.

\section{Acknowledgments}

The authors are grateful for funding from Science Foundation Ireland, Breast Cancer Ireland and the Beaumont Hospital Cancer Research and Development Trust. They also thank other members of the Hopkins laboratory (L. Hudson, S. Donatello, C. Lyes) for helpful discussions.

\section{References}

[1] M. Kásler, C. Polgár, and J. Fodor, "Current status of treatment for early-stage invasive breast cancer," Orvosi Hetilap, vol. 150, no. 22, pp. 1013-1021, 2009.

[2] S. Dey, A. S. Soliman, A. Hablas, et al., "Urban-rural differences in breast cancer incidence by hormone receptor status across 6 years in Egypt," Breast Cancer Research and Treatment 2009, in press.

[3] J. M. Dolle, J. R. Daling, E. White, et al., "Risk factors for triple-negative breast cancer in women under the age of 45 years," Cancer Epidemiology Biomarkers and Prevention, vol. 18, no. 4, pp. 1157-1166, 2009.

[4] B. S. Hulka and P. G. Moorman, "Breast cancer: hormones and other risk factors," Maturitas, vol. 61, no. 1-2, pp. 203213, 2008.

[5] B. Schlehe and R. Schmutzler, "Hereditary breast cancer," Chirurg, vol. 79, no. 11, pp. 1047-1054, 2008.

[6] E. S. Hwang, S. deVries, K. L. Chew, et al., "Patterns of chromosomal alterations in breast ductal carcinoma in situ," Clinical Cancer Research, vol. 10, no. 15, pp. 5160-5167, 2004.

[7] F. Farabegoli, M.-H. Champeme, I. Bieche, et al., "Genetic pathways in the evolution of breast ductal carcinoma in situ," Journal of Pathology, vol. 196, no. 3, pp. 280-286, 2002.

[8] R. Holland, J. L. Peterse, R. R. Millis, et al., "Ductal carcinoma in situ: a proposal for a new classification," Seminars in Diagnostic Pathology, vol. 11, no. 3, pp. 167-180, 1994.

[9] L. Tabar, S. W. Duffy, B. Vitak, et al., "The natural history of breast carcinoma: what have we learned from screening?" Cancer, vol. 86, no. 3, pp. 449-462, 1999.

[10] L. Tabar, G. Fagerberg, H. H. Chen, S. W. Duffy, and A. Gad, "Tumour development, histology and grade of breast cancers: prognosis and progression," International Journal of Cancer, vol. 66, no. 4, pp. 413-419, 1996.

[11] W. S. Al-Dhaheri, I. Hassouna, S. Al-Salam, and S. M. Karam, "Characterization of breast cancer progression in the rat," Annals of the New York Academy of Sciences, vol. 1138, pp. 121-131, 2008.

[12] T. L. Adamovich and R. M. Simmons, "Ductal carcinoma in situ with microinvasion," American Journal of Surgery, vol. 186, no. 2, pp. 112-116, 2003.

[13] A. Cavaliere, M. Scheibel, G. Bellezza, et al., "Ductal carcinoma in situ with microinvasion: clinicopathologic study and biopathologic profile," Pathology Research and Practice, vol. 202, no. 3, pp. 131-135, 2006.

[14] Y. Okumura, Y. Yamamoto, Z. Zhang, et al., "Identification of biomarkers in ductal carcinoma in situ of the breast with microinvasion," BMC Cancer, vol. 8, article 287, 2008.

[15] R. Largillier, J.-M. Ferrero, J. Doyen, et al., "Prognostic factors in 1,038 women with metastatic breast cancer," Annals of Oncology, vol. 19, no. 12, pp. 2012-2019, 2008.

[16] M. J. van de Vijver, Y. D. He, L. J. van 't Veer, et al., "A gene-expression signature as a predictor of survival in breast cancer," New England Journal of Medicine, vol. 347, no. 25, pp. 1999-2009, 2002.

[17] L. J. van 't Veer, H. Dai, M. J. van de Vijver, et al., "Gene expression profiling predicts clinical outcome of breast cancer," Nature, vol. 415, no. 6871, pp. 530-536, 2002.

[18] E. Fuchs, T. Tumbar, and G. Guasch, "Socializing with the neighbors: stem cells and their niche," Cell, vol. 116, no. 6 , pp. 769-778, 2004.

[19] M. Itoh and M. J. Bissell, "The organization of tight junctions in epithelia: implications for mammary gland biology and breast tumorigenesis," Journal of Mammary Gland Biology and Neoplasia, vol. 8, no. 4, pp. 449-462, 2003.

[20] M. Perez-Moreno and E. Fuchs, "Catenins: keeping cells from getting their signals crossed," Developmental Cell, vol. 11, no. 5, pp. 601-612, 2006.

[21] W. J. Nelson, "Adaptation of core mechanisms to generate cell polarity," Nature, vol. 422, no. 6933, pp. 766-774, 2003.

[22] K. Ebnet, "Organization of multiprotein complexes at cellcell junctions," Histochemistry and Cell Biology, vol. 130, no. 1, pp. 1-20, 2008.

[23] M. Furuse, T. Hirase, M. Itoh, et al., "Occludin: a novel integral membrane protein localizing at tight junctions," The Journal of Cell Biology, vol. 123, no. 6, part 2, pp. 1777-1788, 1993.

[24] Y. H. Chen, Q. Lu, D. A. Goodenough, et al., "Nonreceptor tyrosine kinase c-Yes interacts with occludin during tight junction formation in canine kidney epithelial cells," Molecular Biology of the Cell, vol. 13, no. 4, pp. 1227-1237, 2002.

[25] A. Sakakibara, M. Furuse, M. Saitou, Y. Ando-Akatsuka, and S. Tsukita, "Possible involvement of phosphorylation of occludin in tight junction formation," The Journal of Cell Biology, vol. 137, no. 6, pp. 1393-1401, 1997.

[26] A. Y. Andreeva, E. Krause, E. C. Müller, et al., "Protein kinase $\mathrm{C}$ regulates the phosphorylation and cellular localization of occludin," The Journal of Biological Chemistry, vol. 276, no. 42, pp. 38480-38486, 2001.

[27] M. Cordenonsi, F. Turco, F. D'atri, et al., "Xenopus laevis occludin: identification of in vitro phosphorylation sites by protein kinase CK2 and association with cingulin," European Journal of Biochemistry, vol. 264, no. 2, pp. 374-384, 1999.

[28] M. Itoh, M. Furuse, K. Morita, K. Kubota, M. Saitou, and S. Tsukita, "Direct binding of three tight junction-associated MAGUKs, ZO-1, ZO-2, and ZO-3, with the COOH termini 
of claudins," The Journal of Cell Biology, vol. 147, no. 6, pp. 1351-1363, 1999.

[29] G. Krause, L. Winkler, S. L. Mueller, et al., "Structure and function of claudins," Biochimica et Biophysica Acta, vol. 1778, no. 3, pp. 631-645, 2008.

[30] C. M. Van Itallie and J. M. Anderson, "Claudins and epithelial paracellular transport," Annual Review of Physiology, vol. 68, pp. 403-429, 2006.

[31] Y. Sugano, M. Takeuchi, A. Hirata, et al., "Junctional adhesion molecule-A, JAM-A, is a novel cell-surface marker for long-term repopulating hematopoietic stem cells," Blood, vol. 111, no. 3, pp. 1167-1172, 2008.

[32] M. R. Cera, M. Fabbri, C. Molendini, et al., "JAM-A promotes neutrophil chemotaxis by controlling integrin internalization and recycling," Journal of Cell Science, vol. 122, no. 2, pp. 268-277, 2009.

[33] A. Babinska, M. H. Kedees, H. Athar, et al., "F11-receptor (F11R/JAM) mediates platelet adhesion to endothelial cells: role in inflammatory thrombosis," Journal of Thrombosis and Haemostasis, vol. 88, no. 5, pp. 843-850, 2002.

[34] K. Ebnet, M. Aurrand-Lions, A. Kuhn, et al., "The junctional adhesion molecule (JAM) family members JAM-2 and JAM3 associate with the cell polarity protein PAR-3: a possible role for JAMs in endothelial cell polarity," Journal of Cell Science, vol. 116, no. 19, pp. 3879-3891, 2003.

[35] E. A. Severson, W. Y. Lee, C. T. Capaldo, et al., "Junctional adhesion molecule a interacts with afadin and PDZ-GEF2 to activate raplA, regulate $\mathrm{j} 31$ integrin levels, and enhance cell migration," Molecular Biology of the Cell, vol. 20, no. 7, pp. 1916-1925, 2009.

[36] O. M. Martínez-Estrada, A. Villa, F. Breviario, et al., "Association of junctional adhesion molecule with calcium/calmodulin-dependent serine protein kinase (CASK/LIN-2) in human epithelial Caco-2 cells," The Journal of Biological Chemistry, vol. 276, no. 12, pp. 92919296, 2001.

[37] K. Ebnet, C. U. Schulz, M. K. Meyer Zu Brickwedde, et al., "Junctional adhesion molecule interacts with the PDZ domain-containing proteins AF-6 and ZO-1," The Journal of Biological Chemistry, vol. 275, no. 36, pp. 27979-27988, 2000.

[38] K. Ebnet, A. Suzuki, Y. Horikoshi, et al., "The cell polarity protein ASIP/PAR-3 directly associates with junctional adhesion molecule (JAM)," The EMBO Journal, vol. 20, no. 14, pp. 3738-3748, 2001.

[39] C. B. Coyne, T. Voelker, S. L. Pichla, et al., "The coxsackievirus and adenovirus receptor interacts with the multi-PDZ domain protein-1 (MUPP-1) within the tight junction," The Journal of Biological Chemistry, vol. 279, no. 46, pp. 4807948084, 2004.

[40] K. J. D. Ashbourne Excoffon, A. Hruska-Hageman, M. Klotz, et al., "A role for the PDZ-binding domain of the coxsackie $B$ virus and adenovirus receptor (CAR) in cell adhesion and growth," Journal of Cell Science, vol. 117, no. 19, pp. 44014409, 2004.

[41] C. J. Cohen, J. T. C. Shieh, R. J. Pickles, et al., "The coxsackievirus and adenovirus receptor is a transmembrane component of the tight junction," Proceedings of the National Academy of Sciences of the United States of America, vol. 98, no. 26, pp. 15191-15196, 2001.

[42] C. Lemmers, D. Michel, L. Lane-Guermonprez, et al., "CRB3 binds directly to Par6 and regulates the morphogenesis of the tight junctions in mammalian epithelial cells," Molecular Biology of the Cell, vol. 15, no. 3, pp. 1324-1333, 2004.
[43] C. Lemmers, E. Médina, M.-H. Delgrossi, et al., "hINADl/PATJ, a homolog of discs lost, interacts with crumbs and localizes to tight junctions in human epithelial cells," The Journal of Biological Chemistry, vol. 277, no. 28, pp. 25408-25415, 2002.

[44] O. Makarova, M. H. Roh, C. J. Liu, et al., "Mammalian Crumbs 3 is a small transmembrane protein linked to protein associated with Lin-7 (Pals1)," Gene, vol. 302, no. 1-2, pp. 2129, 2003.

[45] M. H. Roh, S. Fan, C.-J. Liu, et al., "The Crumbs3-Pals1 complex participates in the establishment of polarity in mammalian epithelial cells," Journal of Cell Science, vol. 116, no. 14, pp. 2895-2906, 2003.

[46] J. Ikenouchi, M. Furuse, K. Furuse, et al., "Tricellulin constitutes a novel barrier at tricellular contacts of epithelial cells," The Journal of Cell Biology, vol. 171, no. 6, pp. 939-945, 2005.

[47] A. S. Fanning, B. J. Jameson, L. A. Jesaitis, et al., "The tight junction protein ZO-1 establishes a link between the transmembrane protein occludin and the actin cytoskeleton," The Journal of Biological Chemistry, vol. 273, no. 45, pp. 29745-29753, 1998.

[48] E. S. Wittchen, J. Haskins, and B. R. Stevenson, "Protein interactions at the tight junction. Actin has multiple binding partners, and ZO-1 forms independent complexes with ZO-2 and ZO-3," The Journal of Biological Chemistry, vol. 274, no. 49, pp. 35179-35185, 1999.

[49] M. Cordenonsi, F. D’Atri, E. Hammar, et al., "Cingulin contains globular and coiled-coil domains and interacts with ZO-1, ZO-2, ZO-3, and myosin," The Journal of Cell Biology, vol. 147, no. 7, pp. 1569-1582, 1999.

[50] M. H. Roh, C. J. Liu, S. Laurinec, et al., "Involvement of ZO1 in cadherin-based cell adhesion through its direct binding to $\alpha$ catenin and actin filaments," Journal of Cell Biology, vol. 138, no. 1, pp. 181-192, 1997.

[51] M. H. Roh, C.-J. Liu, S. Laurinec, et al., "The carboxyl terminus of zona occludens- 3 binds and recruits a mammalian homologue of discs lost to tight junctions," The Journal of Biological Chemistry, vol. 277, no. 30, pp. 27501-27509, 2002.

[52] T. Kaihara, H. Kawamata, J. Imura, et al., "Redifferentiation and ZO-1 reexpression in liver-metastasized colorectal cancer: possible association with epidermal growth factor receptorinduced tyrosine phosphorylation of ZO-1," Cancer Science, vol. 94, no. 2, pp. 166-172, 2003.

[53] T. Yamamoto, N. Harada, Y. Kawano, et al., "In vivo interaction of AF-6 with activated Ras and ZO-1," Biochemical and Biophysical Research Communications, vol. 259, no. 1, pp. 103-107, 1999.

[54] K. Matter and M. S. Balda, "Epithelial tight junctions, gene expression and nucleo-junctional interplay," Journal of Cell Science, vol. 120, no. 9, pp. 1505-1511, 2007.

[55] A. Tsapara, K. Matter, and M. S. Balda, "The heat-shock protein Apg-2 binds to the tight junction protein $\mathrm{ZO}-1$ and regulates transcriptional activity of ZONAB," Molecular Biology of the Cell, vol. 17, no. 3, pp. 1322-1330, 2006.

[56] L. Su, M. Hattori, M. Moriyama, et al., "AF-6 controls integrin-mediated cell adhesion by regulating Rap1 activation through the specific recruitment of Rap1GTP and SPA1," The Journal of Biological Chemistry, vol. 278, no. 17, pp. 15232-15238, 2003.

[57] T. Asakura, H. Nakanishi, T. Sakisaka, et al., "Similar and differential behaviour between the nectin-afadin-ponsin and cadherin-catenin systems during the formation and 
disruption of the polarized junctional alignment in epithelial cells," Genes Cells, vol. 4, no. 10, pp. 573-581, 1999.

[58] B. Boettner, E.-E. Govek, J. Cross, et al., "The junctional multidomain protein AF-6 is a binding partner of the Rap1A GTPase and associates with the actin cytoskeletal regulator profilin," Proceedings of the National Academy of Sciences of the United States of America, vol. 97, no. 16, pp. 9064-9069, 2000.

[59] I. Dobrosotskaya, R. K. Guy, and G. L. James, "MAGI1, a membrane-associated guanylate kinase with a unique arrangement of protein-protein interaction domains," The Journal of Biological Chemistry, vol. 272, no. 50, pp. 3158931597, 1997.

[60] K. Hirao, Y. Hata, N. Ide, et al., "A novel multiple PDZ domain-containing molecule interacting with $\mathrm{N}$ - methyl-Daspartate receptors and neuronal cell adhesion proteins," The Journal of Biological Chemistry, vol. 273, no. 33, pp. 2110521110, 1998.

[61] Y. Wu, D. Dowbenko, S. Spencer, et al., "Interaction of the tumor suppressor PTEN/MMAC with a PDZ domain of MAGI3, a novel membrane-associated guanylate kinase," The Journal of Biological Chemistry, vol. 275, no. 28, pp. 2147721485, 2000.

[62] K. Adamsky, K. Arnold, H. Sabanay, et al., "Junctional protein MAGI-3 interacts with receptor tyrosine phosphatase $\beta$ (RPTP $\beta$ ) and tyrosine-phosphorylated proteins," Journal of Cell Science, vol. 116, no. 7, pp. 1279-1289, 2003.

[63] F. D’Atri, F. Nadalutti, and S. Citi, "Evidence for a functional interaction between cingulin and $\mathrm{ZO}-1$ in cultured cells," The Journal of Biological Chemistry, vol. 277, no. 31, pp. 2775727764, 2002.

[64] F. D'Atri and S. Citi, "Cingulin interacts with F-actin in vitro," FEBS Letters, vol. 507, no. 1, pp. 21-24, 2001.

[65] G. Bazzoni, O. M. Martínez-Estrada, F. Orsenigo, et al., "Interaction of junctional adhesion molecule with the tight junction components ZO-1, cingulin, and occludin," The Journal of Biological Chemistry, vol. 275, no. 27, pp. 20520 20526, 2000.

[66] S. Paschoud and S. Citi, "Inducible overexpression of cingulin in stably transfected MDCK cells does not affect tight junction organization and gene expression," Molecular Membrane Biology, vol. 25, no. 1, pp. 1-13, 2008.

[67] S. Aijaz, F. D’Atri, M. S. Balda, et al., "Binding of GEF$\mathrm{H} 1$ to the tight junction-associated adaptor cingulin results in inhibition of Rho signaling and G1/S phase transition," Developmental Cell, vol. 8, no. 5, pp. 777-786, 2005.

[68] L. Guillemot and S. Citi, "Cingulin regulates claudin-2 expression and cell proliferation through the small GTPase RhoA," Molecular Biology of the Cell, vol. 17, no. 8, pp. 35693577, 2006.

[69] A. Bratt, W. J. Wilson, B. Troyanovsky, et al., "Angiomotin belongs to a novel protein family with conserved coiled-coil and PDZ binding domains," Gene, vol. 298, no. 1, pp. 69-77, 2002.

[70] Y. Sugihara-Mizuno, M. Adachi, Y. Kobayashi, et al., "Molecular characterization of angiomotin/JEAP family proteins: interaction with MUPP1/Patj and their endogenous properties," Genes to Cells, vol. 12, no. 4, pp. 473-486, 2007.

[71] C. D. Wells, J. P. Fawcett, A. Traweger, et al., "A Rich1/Amot complex regulates the Cdc42 GTPase and apical-polarity proteins in epithelial cells," Cell, vol. 125, no. 3, pp. 535-548, 2006.

[72] K. M. Patrie, "Identification and characterization of a novel tight junction-associated family of proteins that interacts with a WW domain of MAGI-1," Biochimica et Biophysica Acta, vol. 1745, no. 1, pp. 131-144, 2005.

[73] M. Nishimura, M. Kakizaki, Y. Ono, et al., "JEAP, a novel component of tight junctions in exocrine cells," The Journal of Biological Chemistry, vol. 277, no. 7, pp. 5583-5587, 2002.

[74] A. Suzuki, T. Yamanaka, T. Hirose, et al., "Atypical protein kinase $\mathrm{C}$ is involved in the evolutionarily conserved par protein complex and plays a critical role in establishing epitheliaspecific junctional structures," The Journal of Cell Biology, vol. 152, no. 6, pp. 1183-1196, 2001.

[75] S. Sotillos, M. T. Díaz-Meco, E. Caminero, et al., "DaPKCdependent phosphorylation of Crumbs is required for epithelial cell polarity in Drosophila," Journal of Cell Biology, vol. 166, no. 4, pp. 549-557, 2004.

[76] J. M. Mullin, K. V. Laughlin, N. Ginanni, et al., "Increased tight junction permeability can result from protein kinase $\mathrm{C}$ activation/translocation and act as a tumor promotional event in epithelial cancers," Annals of the New York Academy of Sciences, vol. 915, pp. 231-236, 2000.

[77] S. Tsukita, M. Furuse, and M. Itoh, "Multifunctional strands in tight junctions," Nature Reviews Molecular Cell Biology, vol. 2, no. 4, pp. 285-293, 2001.

[78] M. Furuse and S. Tsukita, "Claudins in occluding junctions of humans and flies," Trends in Cell Biology, vol. 16, no. 4, pp. 181-188, 2006.

[79] M. Furuse, H. Sasaki, K. Fujimoto, et al., "A single gene product, claudin-1 or -2 , reconstitutes tight junction strands and recruits occludin in fibroblasts," Journal of Cell Biology, vol. 143, no. 2, pp. 391-401, 1998.

[80] K. Umeda, J. Ikenouchi, S. Katahira-Tayama, et al., “ZO1 and ZO-2 independently determine where claudins are polymerized in tight-junction strand formation," Cell, vol. 126, no. 4, pp. 741-754, 2006.

[81] K. Shin, Q. Wang, and B. Margolis, "PATJ regulates directional migration of mammalian epithelial cells," $E M B O$ Reports, vol. 8, no. 2, pp. 158-164, 2007.

[82] S. Etienne-Manneville, J. B. Manneville, S. Nicholls, et al., "Cdc42 and Par6-PKCzeta regulate the spatially localized association of Dlg1 and APC to control cell polarization," The Journal of Cell Biology, vol. 170, no. 6, pp. 895-901, 2005.

[83] S. Etienne-Manneville and A. Hall, "Integrin-mediated activation of Cdc42 controls cell polarity in migrating astrocytes through PKCzeta," Cell, vol. 106, no. 4, pp. 489-498, 2001.

[84] I. Mellman and W. J. Nelson, "Coordinated protein sorting, targeting and distribution in polarized cells," Nature Reviews Molecular Cell Biology, vol. 9, no. 11, pp. 833-845, 2008.

[85] K. E. Mostov, M. Verges, and Y. Altschuler, "Membrane traffic in polarized epithelial cells," Current Opinion in Cell Biology, vol. 12, no. 4, pp. 483-490, 2000.

[86] G. Berx and F. Van Roy, "The E-cadherin/catenin complex: an important gatekeeper in breast cancer tumorigenesis and malignant progression," Breast Cancer Research, vol. 3, no. 5, pp. 289-293, 2001.

[87] W. Guo and F. G. Giancotti, "Integrin signalling during tumour progression," Nature Reviews Molecular Cell Biology, vol. 5, no. 10, pp. 816-826, 2004.

[88] R. Agarwal, T. D'Souza, and P. J. Morin, "Claudin3 and claudin-4 expression in ovarian epithelial cells enhances invasion and is associated with increased matrix metalloproteinase-2 activity," Cancer Research, vol. 65, no. 16, pp. 7378-7385, 2005.

[89] M. J. Wheelock, A. P. Soler, and K. A. Knudsen, "Cadherin junctions in mammary tumors," Journal of Mammary Gland Biology and Neoplasia, vol. 6, no. 3, pp. 275-285, 2001. 
[90] P. W. B. Derksen, X. Liu, F. Saridin, et al., "Somatic inactivation of E-cadherin and p53 in mice leads to metastatic lobular mammary carcinoma through induction of anoikis resistance and angiogenesis," Cancer Cell, vol. 10, no. 5, pp. 437-449, 2006.

[91] J. Palacios, D. Sarrió, M. C. García-Macias, et al., "Frequent E-cadherin gene inactivation by loss of heterozygosity in pleomorphic lobular carcinoma of the breast," Modern Pathology, vol. 16, no. 7, pp. 674-678, 2003.

[92] T. A. Martin and W. G. Jiang, "Loss of tight junction barrier function and its role in cancer metastasis," Biochimica et Biophysica Acta, vol. 1788, no. 4, pp. 872-891, 2009.

[93] R. Benton and D. St Johnston, "Drosophila PAR-1 and 14-33 inhibit Bazooka/PAR-3 to establish complementary cortical domains in polarized cells," Cell, vol. 115, no. 6, pp. 691-704, 2003.

[94] T. W. Hurd, L. Gao, M. H. Roh, et al., "Direct interaction of two polarity complexes implicated in epthelial tight junction assembly," Nature Cell Biology, vol. 5, no. 2, pp. 137-142, 2003.

[95] S. M. Reuver and C. C. Garner, "E-cadherin mediated cell adhesion recruits SAP97 into the cortical cytoskeleton," Journal of Cell Science, vol. 111, no. 8, pp. 1071-1080, 1998.

[96] H. Wu, S. M. Reuver, S. Kuhlendahl, et al., "Subcellular targeting and cytoskeletal attachment of SAP97 to the epithelial lateral membrane," Journal of Cell Science, vol. 111, no. 16, pp. 2365-2376, 1998.

[97] D. Bilder and N. Perrimon, "Localization of apical epithelial determinants by the basolateral PDZ protein Scribble," Nature, vol. 403, no. 6770, pp. 676-680, 2000.

[98] C. Navarro, S. Nola, S. Audebert, et al., "Junctional recruitment of mammalian Scribble relies on E Cadherin engagement," Oncogene, vol. 24, no. 27, pp. 4330-4339, 2005.

[99] K. Aigner, et al., "The transcription factor ZEB1 (deltaEF1) promotes tumour cell dedifferentiation by repressing master regulators of epithelial polarity," Oncogene, vol. 26, no. 49, pp. 6979-6988, 2007.

[100] X. Wang, et al., "Downregulation of Par-3 expression and disruption of Par complex integrity by TGF- $\beta$ during the process of epithelial to mesenchymal transition in rat proximal epithelial cells," Biochimica et Biophysica Acta, vol. 1782 , no. 1, pp. 51-59, 2008.

[101] D. E. Martin and M. N. Hall, "The expanding TOR signaling network," Current Opinion in Cell Biology, vol. 17, no. 2, pp. 158-166, 2005.

[102] R. J. Shaw and L. C. Cantley, "Ras, PI(3)K and mTOR signalling controls tumour cell growth," Nature, vol. 441, no. 7092, pp. 424-430, 2006.

[103] C. De Virgilio and R. Loewith, "The TOR signalling network from yeast to man," International Journal of Biochemistry and Cell Biology, vol. 38, no. 9, pp. 1476-1481, 2006.

[104] D. Massey-Harroche, M.-H. Delgrossi, L. LaneGuermonprez, et al., "Evidence for a molecular link between the tuberous sclerosis complex and the Crumbs complex," Human Molecular Genetics, vol. 16, no. 5, pp. 529-536, 2007.

[105] D. Michel, J.-P. Arsanto, D. Massey-Harroche, et al., "PATJ connects and stabilizes apical and lateral components of tight junctions in human intestinal cells," Journal of Cell Science, vol. 118, no. 17, pp. 4049-4057, 2005.

[106] J. M. Mullin, "Potential interplay between luminal growth factors and increased tight junction permeability in epithelial carcinogenesis," Journal of Experimental Zoology, vol. 279, no. 5, pp. 484-489, 1997.
[107] S. W. Straight, J. N. Pieczynski, E. L. Whiteman, et al., "Mammalian Lin-7 stabilizes polarity protein complexes," The Journal of Biological Chemistry, vol. 281, no. 49, pp. 37738-37747, 2006.

[108] S. W. Straight, K. Shin, V. C. Fogg, et al., "Loss of PALS1 expression leads to tight junction and polarity defects," Molecular Biology of the Cell, vol. 15, no. 4, pp. 1981-1990, 2004.

[109] Q. Wang, X. W. Chen, and B. Margolis, "PALS1 regulates Ecadherin trafficking in mammalian epithelial cells," Molecular Biology of the Cell, vol. 18, no. 3, pp. 874-885, 2007.

[110] M. E. Nolan, V. Aranda, S. Lee, et al., "The polarity protein Par6 induces cell proliferation and is overexpressed in breast cancer," Cancer Research, vol. 68, no. 20, pp. 8201-8209, 2008.

[111] V. Aranda, M. E. Nolan, and S. K. Muthuswamy, "Par complex in cancer: a regulator of normal cell polarity joins the dark side," Oncogene, vol. 27, no. 55, pp. 6878-6887, 2008.

[112] V. Aranda, T. Haire, M. E. Nolan, et al., "Par6-aPKC uncouples ErbB2 induced disruption of polarized epithelial organization from proliferation control," Nature Cell Biology, vol. 8, no. 11, pp. 1235-1245, 2006.

[113] D. J. Slamon, et al., "Human breast cancer: correlation of relapse and survival with amplification of the HER-2/neu oncogene," Science, vol. 235, no. 4785, pp. 177-182, 1987.

[114] M. Kim, A. Datta, P. Brakeman, et al., "Polarity proteins PAR6 and aPKC regulate cell death through GSK-3 $\beta$ in 3D epithelial morphogenesis," Journal of Cell Science, vol. 120, no. 14, pp. 2309-2317, 2007.

[115] R. P. Regala, C. Weems, L. Jamieson, et al., "Atypical protein kinase $\mathrm{C} \tau$ plays a critical role in human lung cancer cell growth and tumorigenicity," The Journal of Biological Chemistry, vol. 280, no. 35, pp. 31109-31115, 2005.

[116] L. A. Frederick, J. A. Matthews, L. Jamieson, et al., "Matrix metalloproteinase-10 is a critical effector of protein kinase Cı-Par6 $\alpha$-mediated lung cancer," Oncogene, vol. 27, no. 35, pp. 4841-4853, 2008.

[117] K. Zen, et al., "Defective expression of polarity protein PAR3 gene (PARD3) in esophageal squamous cell carcinoma," Oncogene, vol. 28, no. 32, pp. 2910-2918, 2009.

[118] N. Agrawal, S. Joshi, M. Kango, et al., "Epithelial hyperplasia of imaginal discs induced by mutations in Drosophila tumor suppressor genes: growth and pattern formation in genetic mosaics," Developmental Biology, vol. 169, no. 2, pp. 387-398, 1995.

[119] D. Bilder, "Epithelial polarity and proliferation control: links from the Drosophila neoplastictumor suppressors," Genes and Development, vol. 18, no. 16, pp. 1909-1925, 2004.

[120] D. F. Woods and P. J. Bryant, "The discs-large tumor suppressor gene of Drosophila encodes a guanylate kinase homolog localized at septate junctions," Cell, vol. 66, no. 3, pp. 451-464, 1991.

[121] D. Bilder, et al., "Collective nomenclature for LAP proteins," Nature Cell Biology, vol. 2, no. 7, p. E114, 2000.

[122] L. Zhan, A. Rosenberg, K. C. Bergami, et al., "Deregulation of scribble promotes mammary tumorigenesis and reveals a role for cell polarity in carcinoma," Cell, vol. 135, no. 5, pp. 865-878, 2008.

[123] A. Musch, et al., "Mammalian homolog of Drosophila tumor suppressor lethal (2) giant larvae interacts with basolateral exocytic machinery in Madin-Darby canine kidney cells," Molecular Biology of the Cell, vol. 13, no. 1, pp. 158-168, 2002.

[124] L. X. Liu, Z. H. Liu, H. C. Jiang, et al., "Profiling of differentially expressed genes in human gastric carcinoma by 
cDNA expression array," World Journal of Gastroenterology, vol. 8, no. 4, pp. 580-585, 2002.

[125] N. Hanada, K. Makino, H. Koga, et al., "NE-dlg, a mammalian homolog of Drosophila dlg tumor suppressor, induces growth suppression and impairment of cell adhesion: possible involvement of down-regulation of $\beta$-catenin by NE-dlg expression," International Journal of Cancer, vol. 86, no. 4, pp. 480-488, 2000.

[126] T. Ishidate, et al., "The APC-hDLG complex negatively regulates cell cycle progression from the G0/G1 to S phase," Oncogene, vol. 19, no. 3, pp. 365-372, 2000.

[127] H. Hering and M. Sheng, "Direct interaction of Frizzled-1, -2, -4, and -7 with PDZ domains of PSD-95," FEBS Letters, vol. 521, no. 1-3, pp. 185-189, 2002.

[128] R. Z. Karim, G. Tse, T. Putti, et al., "The significance of the Wnt pathway in the pathology of human cancers," Pathology, vol. 36, no. 2, pp. 120-128, 2004.

[129] A. Matsumine, A. Ogai, T. Senda, et al., "Binding of APC to the human homolog of the Drosophila discs large tumor suppressor protein," Science, vol. 272, no. 5264, pp. 1020 1023, 1996.

[130] F. Mantovani, P. Massimi, and L. Banks, "Proteasomemediated regulation of the hDlg tumour suppresor protein," Journal of Cell Science, vol. 114, no. 23, pp. 4285-4292, 2001.

[131] M. Osanai, M. Murata, N. Nishikiori, et al., "Occludinmediated premature senescence is a fail-safe mechanism against tumorigenesis in breast carcinoma cells," Cancer Science, vol. 98, no. 7, pp. 1027-1034, 2007.

[132] H. Tobioka, H. Isomura, Y. Kokai, et al., "Occludin expression decreases with the progression of human endometrial carcinoma," Human Pathology, vol. 35, no. 2, pp. 159-164, 2004.

[133] H. Tobioka, Y. Tokunaga, H. Isomura, et al., "Expression of occludin, a tight-junction-associated protein, in human lung carcinomas," Virchows Archiv, vol. 445, no. 5, pp. 472-476, 2004.

[134] Y. Tokunaga, H. Tobioka, H. Isomura, et al., "Expression of occludin in human rectal carcinoid tumours as a possible marker for glandular differentiation," Histopathology, vol. 44, no. 3, pp. 247-250, 2004.

[135] M. Osanai, et al., "Epigenetic silencing of occludin promotes tumorigenic and metastatic properties of cancer cells via modulations of unique sets of apoptosisassociated genes," Cancer Research, vol. 66, no. 18, pp. 9125-9133, 2006.

[136] T. Hoevel, R. Macek, K. Swisshelm, et al., "Reexpression of the TJ protein CLDN1 induces apoptosis in breast tumor spheroids," International Journal of Cancer, vol. 108, no. 3, pp. 374-383, 2004.

[137] P. Michl, et al., "Claudin-4 expression decreases invasiveness and metastatic potential of pancreatic cancer," Cancer Research, vol. 63, no. 19, pp. 6265-6271, 2003.

[138] S. Mima, S. Tsutsumi, H. Ushijima, et al., "Induction of claudin- 4 by nonsteroidal anti-inflammatory drugs and its contribution to their chemopreventive effect," Cancer Research, vol. 65, no. 5, pp. 1868-1876, 2005.

[139] K. Swisshelm, A. Machl, S. Planitzer, et al., "SEMP1, a senescence-associated cDNA isolated from human mammary epithelial cells, is a member of an epithelial membrane protein superfamily," Gene, vol. 226, no. 2, pp. 285-295, 1999.

[140] M. Osanai, et al., "Epigenetic silencing of claudine-6 promotes anchorage independent growth of breast carcinoma cells," Cancer Science, vol. 98, no. 10, pp. 1557-1562, 2007.

[141] J. M. Mullin, "Epithelial barriers, compartmentation, and cancer," Science's STKE, vol. 2004, no. 216, p. pe2, 2004.
[142] A. M. Tokés, et al., "Claudin-1, -3 and -4 proteins and mRNA expression in benign and malignant breast lesions: a research study," Breast Cancer Research, vol. 7, no. 2, pp. R296-R305, 2005.

[143] S. L. Kominsky, M. Vali, D. Korz, et al., "Clostridium perfringens enterotoxin elicits rapid and specific cytolysis of breast carcinoma cells mediated through tight junction proteins claudin 3 and 4," American Journal of Pathology, vol. 164, no. 5, pp. 1627-1633, 2004.

[144] F. Lanigan, E. McKiernan, D. J. Brennan, et al., "Increased claudin-4 expression is associated with poor prognosis and high tumour grade in breast cancer," International Journal of Cancer, vol. 124, no. 9, pp. 2088-2097, 2009.

[145] K. J. Hewitt, R. Agarwal, and P. J. Morin, "The claudin gene family: expression in normal and neoplastic tissues," BMC Cancer, vol. 6, article 186, 2006.

[146] K. B. Hoover, S. Y. Liao, and P. J. Bryant, "Loss of the tight junction MAGUK ZO-1 in breast cancer: relationship to glandular differentiation and loss of heterozygosity," American Journal of Pathology, vol. 153, no. 6, pp. 1767-1773, 1998.

[147] T. Kaihara, et al., "Dedifferentiation and decreased expression of adhesion molecules, E-cadherin and ZO-1, in colorectal cancer are closely related to liver metastasis," Journal of Experimental and Clinical Cancer Research, vol. 22, no. 1, pp. 117-123, 2003.

[148] M. S. Balda, M. D. Garrett, and K. Matter, "The ZO1-associated Y-box factor ZONAB regulates epithelial cell proliferation and cell density," The Journal of Cell Biology, vol. 160, no. 3, pp. 423-432, 2003.

[149] P. Frankel, A. Aronheim, E. Kavanagh, et al., "Ra1A interacts with ZONAB in a cell density-dependent manner and regulates its transcriptional activity," EMBO Journal, vol. 24, no. 1, pp. 54-62, 2005.

[150] M. Huerta, R. Muñoz, R. Tapia, et al., "Cyclin D1 is transcriptionally down-regulated by $\mathrm{ZO}-2$ via an $\mathrm{E}$ box and the transcription factor c-Myc," Molecular Biology of the Cell, vol. 18, no. 12, pp. 4826-4836, 2007.

[151] M. S. Balda and K. Matter, "The tight junction protein ZO1 and an interacting transcription factor regulate ErbB-2 expression," EMBO Journal, vol. 19, no. 9, pp. 2024-2033, 2000.

[152] H. Wang, et al., "C/EBPalpha arrests cell proliferation through direct inhibition of Cdk2 and Cdk4," Molecular Cell, vol. 8, no. 4, pp. 817-828, 2001.

[153] S. Samarin and A. Nusrat, "Regulation of epithelial apical junctional complex by Rho family GTPases," Frontiers in Bioscience, vol. 14, pp. 1129-1142, 2009.

[154] F. Grise, A. Bidaud, and V. Moreau, "Rho GTPases in hepatocellular carcinoma," Biochimica et Biophysica Acta, vol. 1795, no. 2, pp. 137-151, 2009.

[155] M. L. Coleman, C. J. Marshall, and M. F. Olson, "RAS and RHO GTPases in G1-phase cell-cycle regulation," Nature Reviews Molecular Cell Biology, vol. 5, no. 5, pp. 355-366, 2004.

[156] S. Mizuarai, K. Yamanaka, and H. Kotani, "Mutant p53 induces the GEF-H1 oncogene, a guanine nucleotide exchange factor-H1 for RhoA, resulting in accelerated cell proliferation in tumor cells," Cancer Research, vol. 66, no. 12, pp. 6319-6326, 2006.

[157] M. Mareel and A. Leroy, "Clinical, cellular, and molecular aspects of cancer invasion," Physiological Reviews, vol. 83, no. 2, pp. 337-376, 2003. 
[158] E. A. McSherry, S. Donatello, A. M. Hopkins, et al., "Molecular basis of invasion in breast cancer," Cellular and Molecular Life Sciences, vol. 64, no. 24, pp. 3201-3218, 2007.

[159] B. T. Hennessy, A.-M. Gonzalez-Angulo, K. Stemke-Hale, et al., "Characterization of a naturally occurring breast cancer subset enriched in epithelial-to-mesenchymal transition and stem cell characteristics," Cancer Research, vol. 69, no. 10, pp. 4116-4124, 2009.

[160] A. A. Blanchard, G. P. Skliris, P. H. Watson, et al., "Claudins 1,3 , and 4 protein expression in ER negative breast cancer correlates with markers of the basal phenotype," Virchows Archiv, vol. 454, no. 6, pp. 647-656, 2009.

[161] F. Kramer, et al., "Genomic organization of claudin-1 and its assessment in hereditary and sporadic breast cancer," Human Genetics, vol. 107, no. 3, pp. 249-256, 2000.

[162] S. Morohashi, T. Kusumi, F. Sato, et al., "Decreased expression of claudin- 1 correlates with recurrence status in breast cancer," International Journal of Molecular Medicine, vol. 20, no. 2, pp. 139-143, 2007.

[163] T. H. Kim, J. H. Huh, S. Lee, et al., "Down-regulation of claudin-2 in breast carcinomas is associated with advanced disease," Histopathology, vol. 53, no. 1, pp. 48-55, 2008.

[164] S. L. Kominsky, P. Argani, D. Korz, et al., "Loss of the tight junction protein claudin-7 correlates with histological grade in both ductal carcinoma in situ and invasive ductal carcinoma of the breast," Oncogene, vol. 22, no. 13, pp. 20212033, 2003.

[165] T. A. Martin, G. M. Harrison, G. Watkins, et al., "Claudin16 reduces the aggressive behavior of human breast cancer cells," Journal of Cellular Biochemistry, vol. 105, no. 1, pp. 4152, 2008.

[166] T. Sauer, M. K. Pedersen, K. Ebeltoft, et al., "Reduced expression of Claudin-7 in fine needle aspirates from breast carcinomas correlate with grading and metastatic disease," Cytopathology, vol. 16, no. 4, pp. 193-198, 2005.

[167] Y. Soini, "Expression of claudins 1, 2, 3, 4, 5 and 7 in various types of tumours," Histopathology, vol. 46, no. 5, pp. 551-560, 2005.

[168] F. Jaulin-Bastard, H. Saito, A. Le Bivic, et al., "The ERBB2/HER2 receptor differentially interacts with ERBIN and PICK1 PSD-95/DLG/ZO-1 domain proteins," The Journal of Biological Chemistry, vol. 276, no. 18, pp. 15256-15263, 2001.

[169] T. W. Liang, et al., "Characterization of huJAM: evidence for involvement in cellcell contact and tight junction regulation," American Journal of Physiology, vol. 279, no. 6, pp. C1733C1743, 2000.

[170] K. J. Mandell, B. A. Babbin, A. Nusrat, et al., "Junctional adhesion molecule 1 regulates epithelial cell morphology through effects on $\beta 1$ integrins and Rap1 activity," The Journal of Biological Chemistry, vol. 280, no. 12, pp. 11665 11674, 2005.

[171] I. Martìn-Padura, S. Lostaglio, M. Schneemann, et al., "Junctional adhesion molecule, a novel member of the immunoglobulin superfamily that distributes at intercellular junctions and modulates monocyte transmigration," Journal of Cell Biology, vol. 142, no. 1, pp. 117-127, 1998.

[172] G. Ostermann, et al., "AM-1 is a ligand of the $\beta(2)$ integrin LFA-1 involved in transendothelial migration of leukocyte," Nature Immunology, vol. 3, no. 2, pp. 151-158, 2002.

[173] E. A. McSherry, S. F. McGee, K. Jirstrom, et al., "JAM-A expression positively correlates with poor prognosis in breast cancer patients," International Journal of Cancer, vol. 125, no. 6, pp. 1343-1351, 2009.
[174] M. U. Naik, T. U. Naik, A. T. Suckow, et al., "Attenuation of junctional adhesion molecule-A is a contributing factor for breast cancer cell invasion," Cancer Research, vol. 68, no. 7, pp. 2194-2203, 2008.

[175] M. Bordin, et al., "Histone deacetylase inhibitors up-regulate the expression of tight junction proteins," Molecular Cancer Research, vol. 2, no. 12, pp. 692-701, 2004.

[176] G. Mandicourt, S. Iden, K. Ebnet, et al., "JAM-C regulates tight junctions and integrin-mediated cell adhesion and migration," The Journal of Biological Chemistry, vol. 282, no. 3, pp. 1830-1837, 2007.

[177] T. A. Martin, G. Watkins, R. E. Mansel, et al., "Loss of tight junction plaque molecules in breast cancer tissues is associated with a poor prognosis in patients with breast cancer," European Journal of Cancer, vol. 40, no. 18, pp. 27172725, 2004.

[178] M. Polette, et al., "Membrane-type 1 matrix metalloproteinase expression is regulated by zonula occludens- 1 in human breast cancer cells," Cancer Research, vol. 65, no. 17, pp. 7691-7698, 2005.

[179] M. S. Balda, C. Flores-Maldonado, M. Cereijido, et al., "Multiple domains of occludin are involved in the regulation of paracellular permeability," The Journal of Cellular Biochemistry, vol. 78, no. 1, pp. 85-96, 2000.

[180] A. Chlenski, et al., "Organization and expression of the human zo-2 gene (tjp-2) in normal and neoplastic tissues," Biochimica et Biophysica Acta, vol. 1493, no. 3, pp. 319-324, 2000.

[181] B. A. Glaunsinger, R. S. Weiss, S. S. Lee, et al., "Link of the unique oncogenic properties of adenovirus type 9 E4-ORF1 to a select interaction with the candidate tumor suppressor protein ZO-2," EMBO Journal, vol. 20, no. 20, pp. 5578-5586, 2001.

[182] D. M. Pegtel, S. I. J. Ellenbroek, A. E. E. Mertens, et al., "The Par-Tiam1 complex controls persistent migration by stabilizing microtubule-dependent front-rear polarity," Current Biology, vol. 17, no. 19, pp. 1623-1634, 2007.

[183] M. E. Minard, L. S. Kim, J. E. Price, et al., "The role of the guanine nucleotide exchange factor Tiam1 in cellular migration, invasion, adhesion and tumor progression," Breast Cancer Research and Treatment, vol. 84, no. 1, pp. 2132, 2004.

[184] G. Joberty, C. Petersen, L. Gao, et al., "The cell-polarity protein Par6 links Par3 and atypical protein kinase C to Cdc42," Nature Cell Biology, vol. 2, no. 8, pp. 531-539, 2000.

[185] B. Ozdamar, et al., "Regulation of the polarity protein Par6 by TGF $\beta$ receptors controls epithelial cell plasticity," Science, vol. 307, no. 5715, pp. 1603-1609, 2005.

[186] L. Y. W. Bourguignon, Z. Hongbo, L. Shao, et al., "CD44 interaction with Tiam1 promotes Rac1 signaling and hyaluronic acid-mediated breast tumor cell migration," The Journal of Biological Chemistry, vol. 275, no. 3, pp. 18291838, 2000.

[187] P. J. Keely, J. K. Westwick, I. P. Whitehead, et al., "Cdc42 and Racl induce integrin-mediated cell motility and invasiveness through PI(3)K," Nature, vol. 390, no. 6660, pp. 632-636, 1997.

[188] M. Itoh, C. M. Nelson, C. A. Myers, et al., "Rap1 integrates tissue polarity, lumen formation, and tumorigenic potential in human breast epithelial cells," Cancer Research, vol. 67, no. 10, pp. 4759-4766, 2007.

[189] B. H. Shieh, L. Parker, and D. Popescu, "Protein kinase C (PKC) isoforms in Drosophila," The Journal of Biochemistry, vol. 132, no. 4, pp. 523-527, 2002. 
[190] Y. Kojima, K. Akimoto, Y. Nagashima, et al., “The overexpression and altered localization of the atypical protein kinase $\mathrm{C} \lambda / \iota$ in breast cancer correlates with the pathologic type of these tumors," Human Pathology, vol. 39, no. 6, pp. 824-831, 2008.

[191] X. G. Sun and S. A. Rotenberg, "Overexpression of protein kinase Calpha in MCF- 10A human breast cells engenders dramatic alterations in morphology, proliferation, and motility," Cell Growth \& Differentiation, vol. 10, no. 5, pp. 343-352, 1999.

[192] Y. Soini, "Claudins 2, 3, 4, and 5 in Paget's disease and breast carcinoma," Human Pathology, vol. 35, no. 12, pp. 15311536, 2004.

[193] A. A. Blanchard, G. P. Skliris, P. H. Watson, et al., "Claudins 1,3 , and 4 protein expression in ER negative breast cancer correlates with markers of the basal phenotype," Virchows Archiv, vol. 454, no. 6, pp. 647-656, 2009.

[194] P. Michl, et al., "Claudin-4: a new target for pancreatic cancer treatment using clostridium perfringens enterotoxin," Gastroenterology, vol. 121, no. 3, pp. 678-684, 2001.

[195] A. D. Santin, S. Bellone, M. Marizzoni, et al., "Overexpression of claudin-3 and claudin-4 receptors in uterine serous papillary carcinoma: novel targets for a type-specific therapy using Clostridium perfringens enterotoxin (CPE)," Cancer, vol. 109, no. 7, pp. 1312-1322, 2007.

[196] P. J. Morin, "Claudin proteins in human cancer: promising new targets for diagnosis and therapy," Cancer Research, vol. 65, no. 21, pp. 9603-9606, 2005.

[197] J. Katahira, H. Sugiyama, N. Inoue, et al., "Clostridium perfringens enterotoxin utilizes two structurally related membrane proteins as functional receptors in vivo," The Journal of Biological Chemistry, vol. 272, no. 42, pp. 2665226658, 1997.

[198] J. Katahira, N. Inoue, Y. Horiguchi, et al., "Molecular cloning and functional characterization of the receptor for Clostridium perfringens enterotoxin," Journal of Cell Biology, vol. 136, no. 6, pp. 1239-1247, 1997.

[199] M. Kondoh, A. Takahashi, M. Fujii, et al., "A novel strategy for a drug delivery system using a claudin modulator," Biological and Pharmaceutical Bulletin, vol. 29, no. 9, pp. 1783-1789, 2006.

[200] B. A. McClane and G. Chakrabarti, "New insights into the cytotoxic mechanisms of Clostridium perfringens enterotoxin," Anaerobe, vol. 10, no. 2, pp. 107-114, 2004.

[201] C. Ebihara, M. Kondoh, N. Hasuike, et al., "Preparation of a claudin-targeting molecule using a C-terminal fragment of Clostridium perfringens enterotoxin," Journal of Pharmacology and Experimental Therapeutics, vol. 316, no. 1, pp. 255260, 2006.

[202] A. Gadducci, R. Tana, S. Cosio, et al., "Molecular target therapies in endometrial cancer: from the basic research to the clinic," Gynecological Endocrinology, vol. 24, no. 5, pp. 239-249, 2008.

[203] S. Offner, A. Hekele, U. Teichmann, et al., "Epithelial tight junction proteins as potential antibody targets for pancarcinoma therapy," Cancer Immunology, Immunotherapy, vol. 54, no. 5, pp. 431-445, 2005.

[204] E. Raschperger, et al., "The coxsackie- and adenovirus receptor (CAR) is an in vivo marker for epithelial tight junctions, with a potential role in regulating permeability and tissue homeostasis," Experimental Cell Research, vol. 312, no. 9, pp. 1566-1580, 2006.

[205] L. Philipson and R. F. Pettersson, "The coxsackie-adenovirus receptor-a new receptor in the immunoglobulin family involved in cell adhesion," Current Topics in Microbiology and Immunology, vol. 273, pp. 87-111, 2004.

[206] T. A. Martin, G. Watkins, and W. G. Jiang, "The Coxsackieadenovirus receptor has elevated expression in human breast cancer," Clinical and Experimental Medicine, vol. 5, no. 3, pp. 122-128, 2005.

[207] C. B. Coyne and J. M. Bergelson, "CAR: a virus receptor within the tight junction," Advanced Drug Delivery Reviews, vol. 57, no. 6, pp. 869-882, 2005.

[208] V. Wong and B. M. Gumbiner, "A synthetic peptide corresponding to the extracellular domain of occludin perturbs the tight junction permeability barrier," The Journal of Cell Biology, vol. 136, no. 2, pp. 399-409, 1997.

[209] M. Kondoh, T. Yoshida, H. Kakutani, et al., "Targeting tight junction proteins-significance for drug development," Drug Discovery Today, vol. 13, no. 3-4, pp. 180-186, 2008.

[210] A. Nusrat, J. A. Chen, C. S. Foley, et al., "The coiledcoil domain of occludin can act to organize structural and functional elements of the epithelial tight junction," The Journal of Biological Chemistry, vol. 275, no. 38, pp. 2981629822, 2000.

[211] Z. Wang, K. J. Mandell, C. A. Parkos, et al., "The second loop of occludin is required for suppression of Rafl-induced tumor growth," Oncogene, vol. 24, no. 27, pp. 4412-4420, 2005.

[212] L. González-Mariscal, P. Nava, and S. Hernández, "Critical role of tight junctions in drug delivery across epithelial and endothelial cell layers," Journal of Membrane Biology, vol. 207, no. 2, pp. 55-68, 2005.

[213] K. Matsuhisa, et al., "Tight junction modulator and drug delivery," Expert Opinion on Drug Delivery, vol. 6, no. 5, pp. 509-515, 2009.

[214] E. E. Schneeberger and R. D. Lynch, "The tight junction: a multifunctional complex," American Journal of Physiology, vol. 286, no. 6, pp. C1213-C1228, 2004. 

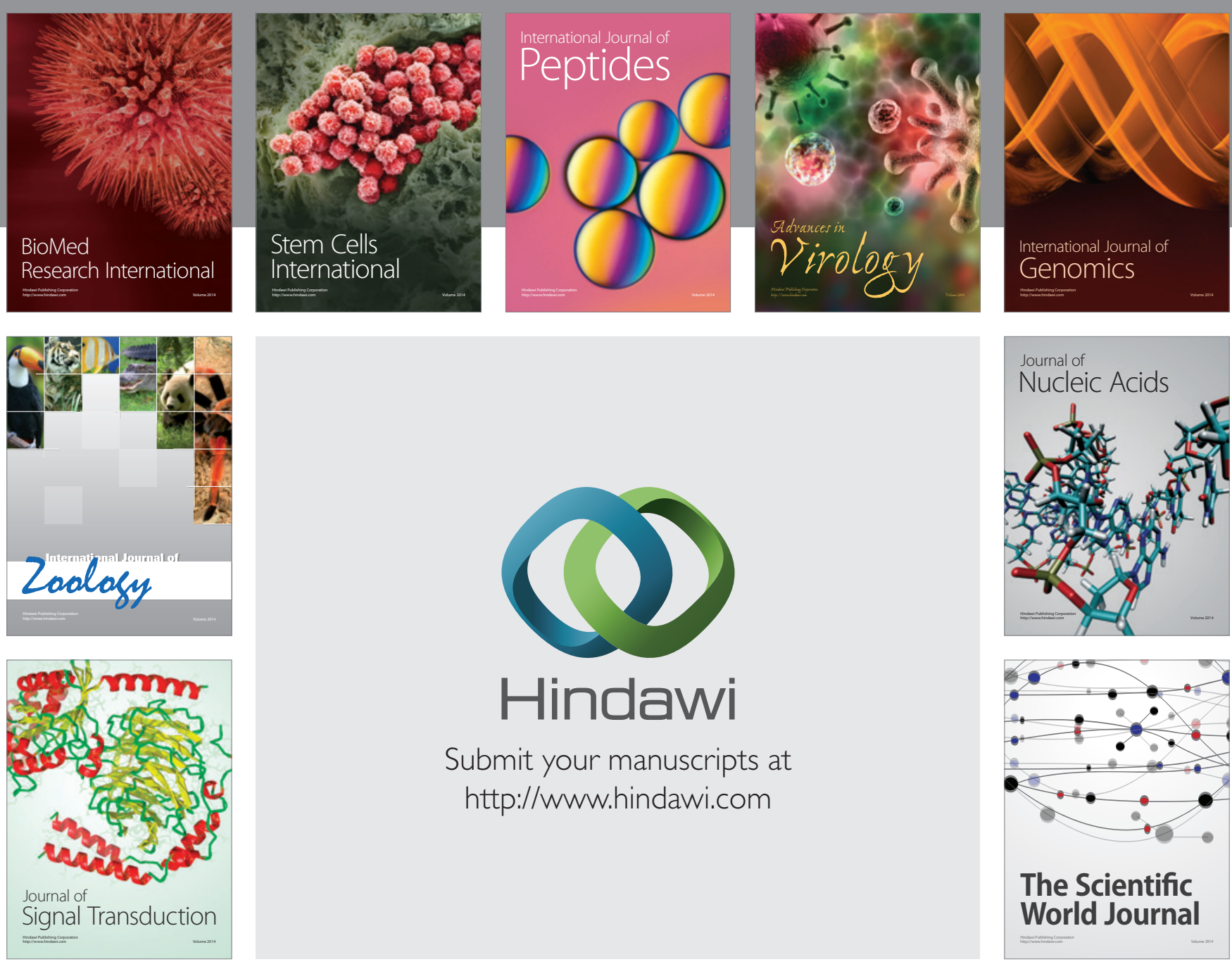

Submit your manuscripts at

http://www.hindawi.com
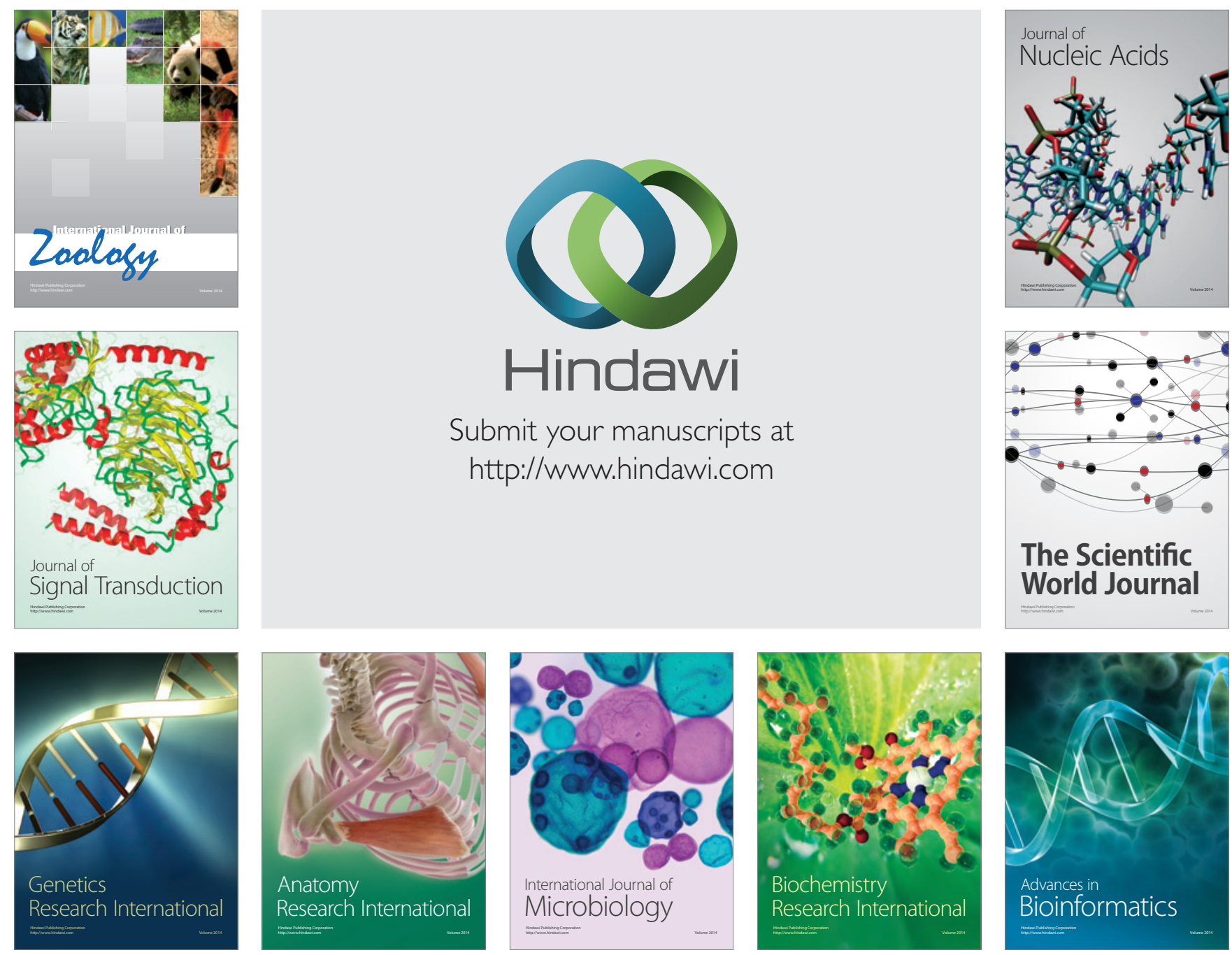

The Scientific World Journal
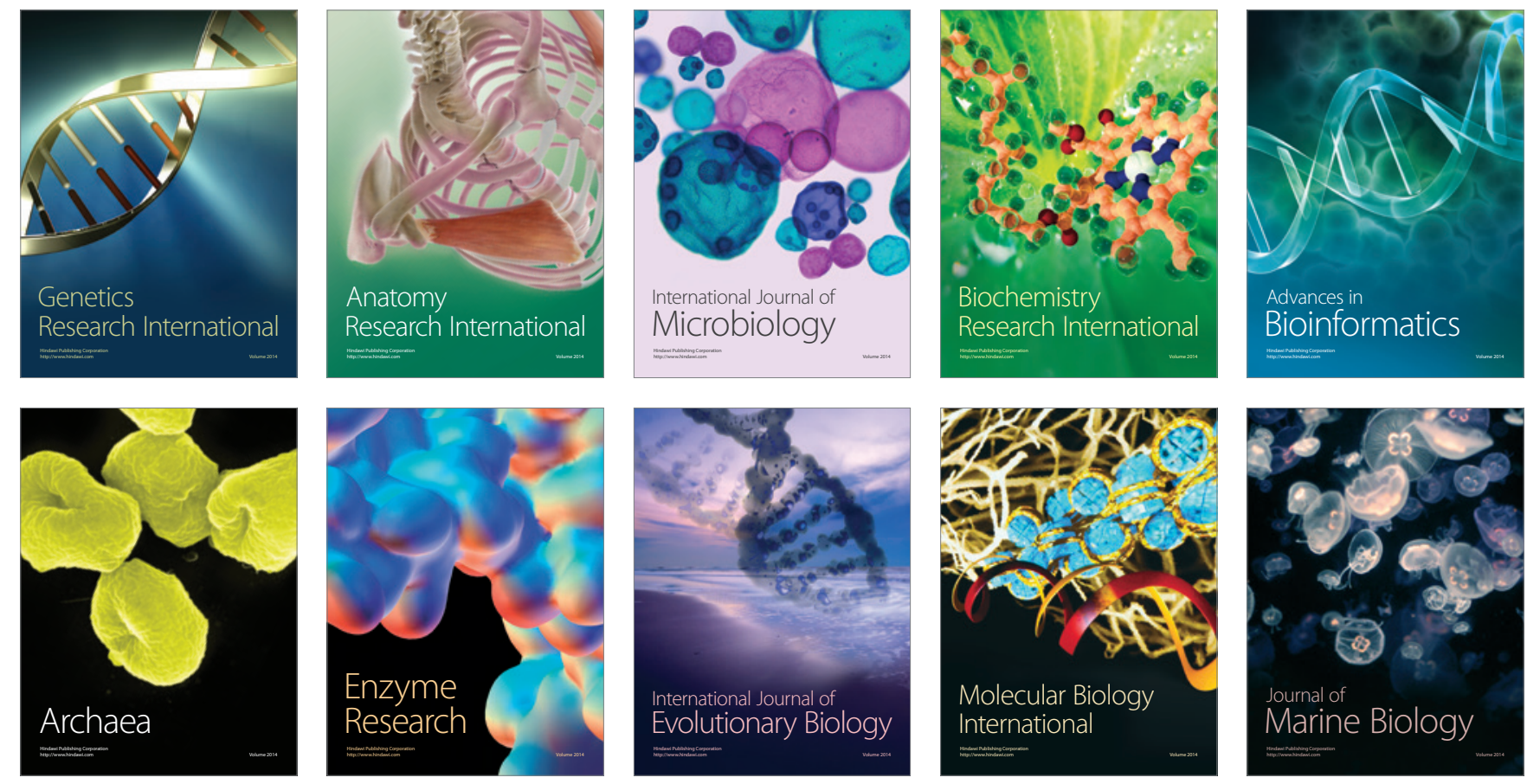